\title{
Developing a hierarchical framework for assessing the strategic effectiveness of sustainable waste management in Somaliland construction industry
}

Yeneneh Tamirat Negash

Asia University

Abdiqani Muse Hassan

University of Hargeisa

Ming-Lang Tseng ( $\nabla$ tsengminglang@gmail.com )

Asia University https://orcid.org/0000-0002-2702-3590

Mohd Helmi Ali

Universiti Kebangsaan Malaysia

Ming K. Lim

University of Glasgow

\section{Research Article}

Keywords: strategic effectiveness, sustainable waste management, construction \& demolition waste, best-worst method, fuzzy Delphi, fuzzy interpretive structural modeling

Posted Date: February 21st, 2022

DOI: https://doi.org/10.21203/rs.3.rs-1215162/v1

License: (c) (i) This work is licensed under a Creative Commons Attribution 4.0 International License.

Read Full License 
Developing a hierarchical framework for assessing the strategic effectiveness of sustainable waste management in Somaliland construction industry

3

\section{Yeneneh Tamirat Negash}

- Institute of Innovation and Circular Economy, Asia University, Taiwan

- Department of Business Administration, College of Management, Asia University, Taiwan E-mail: yeneneh@asia.edu.tw; yenuta@gmail.com

\section{Abdiqani Muse Hassan}

- Department of Business Administration, Asia University, Taiwan

- Department of Civil Engineering, University of Hargeisa, Somaliland

Email: engabdikani@gmail.com

Ming-Lang Tseng (Corresponding Author) (Google h-index: 59; Scopus H-index: 48)

- Institute of Innovation and Circular Economy, Asia University Taiwan, Taichung, Taiwan

- Department of Medical Research, China Medical University Hospital, China Medical University, Taichung, Taiwan

E-mail: tsengminglang@gmail.com; tsengminglang@asia.edu.tw

\section{Mohd Helmi Ali}

- UKM Graduate School of Business, Universiti Kebangsaan Malaysia, 43600 UKM Bangi, Selangor, Malaysia 

waste management in Somaliland construction industry

\section{Abstract}

This study contributes to the literature by developing a hierarchical framework for assessing the strategic effectiveness of waste management in the construction industry. This study identifies a valid set of strategic effectiveness attributes of sustainable waste management in construction. Prior studies have neglected to develop sustainable waste management's strategic effectiveness assessment framework to identify reuse and recycle policy initiatives that ensure waste minimization and resource recovery programs. This study utilizes the fuzzy Delphi method to screen out nonessential attributes in qualitative information. Fuzzy interpretive structural modeling divides the attributes into various elements. It constructs a multilevel model that depicts the interrelationships among the attributes into a hierarchical framework and finds and ranks the optimal drivers for practical improvement. This study integrates the best-worst method to measure different criteria' weights in the hierarchical strategic effectiveness framework. The findings reveal that waste management operations strategy, construction site waste management performance, and mutual coordination are the top aspects for assessing strategic effectiveness in the hierarchical framework. In practice, the waste reduction rate, recycling rate, reuse rate and noise and air pollution levels are identified to assist policymakers in evaluation. The theoretical and managerial implications are discussed

keywords: strategic effectiveness; sustainable waste management; construction \& demolition waste; best-worst method; fuzzy Delphi; fuzzy interpretive structural modeling 
Developing a hierarchical framework for assessing the strategic effectiveness of sustainable waste management in Somaliland construction industry

\section{Introduction}

Construction and demolition waste generation are increasing, and this waste constitutes approximately $25-35 \%$ of all solid waste generated world wide (Bao \& Lu, 2020; Lu et al., 2019). Proper waste management strategy is crucial for construction activities due to impacts on the economy, society, and environment (the triple bottom line, TBL) (Aslam et al., 2020; Xu et al., 2019; Marrero et al., 2017). Sustainable waste management (SWM) is necessary to mitigate and overcome negative TBL consequences and create reuse and recycle value from construction waste (Ahangar et al., 2021; Ghaffar et al., 2020; Huang et al., 2018). The strategic effectiveness assessment framework of SWM is needed to identify reuse and recycle policy initiatives that ensure waste minimization and resource recovery programs (Lavigne et al., 2019; Yuan, 2013). In addition, construction firms became more interested in SWM alternatives instead of landfilling, including reuse, recycling, and energy recovery and treatment to remove toxic components. Even though the interest of construction firms and consumers in building an SWM system continues to grow, a framework for assessing its strategic effectiveness is lacking, resulting in reduce, reuse and recycling (3Rs) challenges (Aslam et al., 2020; Kabirifar et al., 2020; Wu et al., 2019). Indeed, SWM in construction needs a strategic effectiveness assessment framework to understand the challenges and opportunities in solving environmental and social problems.

The strategic effectiveness attributes of SWM enable assessing the current SWM situation, providing implementation guidelines, and monitoring the progress made toward 3Rs objectives. However, the lack of sufficient attention to evaluating the strategic effectiveness of SWM remains an obstacle to improvement (Ahangar et al., 2021; Aslam et al., 2020; Wu et al., 2019; Yuan et al., 2012). Kabirifar et al. (2020) argued that the strategic effectiveness framework of SWM for evaluation has been ignored; this framework assists in reusing and recycling policymaking and performance evaluation. Therefore, developing a hierarchical framework integrating SWM strategic effectiveness attributes is necessary to address this need. Thus, this study develops the strategic effectiveness hierarchical framework of SWM to manage the construction industry's environmental and social problems and 3Rs challenges.

Prior studies have applied waste management strategies, financial and economic enablers and environmental pressure to assess the strategic effectiveness of SWM (Bui \& Tseng, 2021; Khan et al., 2021; Perteghella et al., 2020). Nevertheless, Goh et al. (2020) argued that these attributes are not sufficient to measure site waste management performance due to the unique decentralized nature of construction waste, difficulties in stakeholder collaboration and poor regulatory practices. Technology and regulatory support can aid in improving the efficiency of reuse and recycling goals. Hence, this study integrates technological and regulatory attributes to assess the strategic effectiveness of SWM. Du et al. (2020) indicated that regulatory attributes are critical to achieving reuse and recycling goals because they prevent illegal waste disposal and promote sustainable practices in waste generation and disposal through penalties and subsidies. Jin et al. (2019) emphasized technological consideration to produce the desired outcomes; technological adaptation is increasing and has been indicated to benefit quantification and waste reuse and recycling activities. Chen et al. (2019) argued that regulatory attributes, such as policymaking and government interventions, are significant for providing the necessary guidelines and ensuring the practical implementation of strategic effectiveness. In addition, Li et al. (2020) claimed that technology 
120 integration enhances the strategic effectiveness of SWM by providing prerequisite 121 information for planning, estimating and tracking performance. Hence, a holistic approach is required for SWM strategic effectiveness assessment in construction. A holistic approach must integrate policy and regulatory support and environmental technologies with waste management strategies and financial and economic enablers to improve site waste management performance for construction firms.

The lack of an integrative SWM hierarchical framework for assessing strategic effectiveness has led to significant managerial challenges and poor site waste management practices (Aslam et al., 2020; Kabirifar et al., 2020; Wu et al., 2019). The attributes must be valid for construction industry measures. Prior studies have failed to carry out validation and lack exploration of the hierarchical relationships between SWM strategic effectiveness attributes (Kabirifar et al., 2020; Wu et al., 2019; Yuan et al., 2012). The attributes are qualitative and subject to uncertainty because of the experts' linguistic preferences (Negash \& Hassan, 2020; Tseng et al., 2019). Prior studies have failed to consider the uncertainties arising from linguistic preferences in developing measurement attributes (Sadeghi et al., 2021; Wu et al., 2019; Yuan et al., 2012). This study employs fuzzy set theory to address linguistic preference and fuzzy membership functions. It combines the fuzzy Delphi method (FDM) and fuzzy interpretive structural modeling (FISM) to assess the SWM strategic effectiveness attributes in qualitative information. The FDM was applied to remove nonessential attributes and formulate a set of valid attributes (Bui et al., 2020; Negash \& Hassan, 2020). The FISM was employed to organize the attributes into a hierarchical framework to develop measurements for the strategic effectiveness of SWM (Alnajem et al., 2021; Tsai et al., 2020; Negash et al., 2021). This study integrates the best-worst method (BWM) to analyze the weights of different criteria in the SWM strategic effectiveness hierarchical framework (Zhang et al., 2017; Rezaei, 2015). The study objectives are as follows:

- To identify a valid set of SWM strategic effectiveness attributes in qualitative information.

- To develop a hierarchical framework for assessing SWM strategic effectiveness in construction under uncertainties.

- To determine the construction industry SWM strategic effectiveness assessment criteria for its practical improvement.

The contributions of this study are as follows: (1) proposing a set of valid attributes to evaluate and understand the strategic effectiveness of SWM in construction; (2) providing guidelines to estimate SWM progress toward management targets and intended goals; and (3) presenting criteria that assist decision-makers in forming an effective SWM strategy for performance enhancement. The rest of this study is organized as follows. The following section discusses the literature on the strategic effectiveness of SWM, proposed methods and proposed attributes. The methodologies adopted in the study are discussed in the third section. The fourth section presents the case background and the study results. The theoretical and managerial implications are discussed in section five. Finally, the conclusions, limitations and suggestions for future research are discussed in the last section.

\section{Literature Review}

\subsection{Sustainable waste management in construction}

SWM in construction aims to minimize environmental and social threats while maintaining the economic growth of construction firms (Aslam et al., 2020; Yuan et al., 2018; Yuan et al., 2017). Prior studies have discussed SWM strategies to reduce, recycle and reuse waste 
2020; Hao et al., 2019; Borghi et al., 2018). The environmental goals evaluate a construction project's performance in tracking and tackling ecological threats. For instance, Esa et al. (2017) addressed environmental goals to develop an integrated management framework for waste minimization strategies. Borghi et al. (2018) provided a framework from an environmental viewpoint to evaluate the weaknesses of waste management and offer improvement strategies. Social goals are related to the standards by which firms operate, such as stakeholders' practices, behaviors, norms, and values. Bao and Lu (2020) linked SWM with social attributes that enable higher effectiveness and trigger ambitions for waste treatment. The economic goals focus on financial gains and reducing costs while decoupling social and environmental hazards. Hao et al. (2019) discussed economic plans that assist in designing SWM policies and improving their implementation. Yet, the studies mentioned above focused on reducing environmental burdens and improving financial performance but neglected to integrate reusing and recycling objectives in the construction industry (Ghaffar et al., 2020).

SWM strategies in construction require technology usage to decrease environmental impacts, deliver social benefits, and secure economic growth (Khan et al., 2021; Ghaffar et al., 2020; Goh et al., 2020). The technological perspective refers to firms' operations, degree of technology usage, innovations, and practical decisions that influence reusing and recycling objectives. However, poor technological adoption has resulted in reusing and recycling challenges restraining the shift toward sustainability (Bui \& Tseng, 2021; Li et al., 2020; Won \& Cheng, 2017). Jin et al. (2019) argued that combining technological attributes assists reusing and recycling objectives by minimizing the risks involved in sustainability practices and providing platforms for predicting management outcomes. Li et al. (2019) highlighted that SWM strategic planning, tracking operations, evaluating implementation progress and performance require emerging technologies. Bao and Lu (2020) asserted that although technology enhances SWM, there are limitations involving the economic capability of developing and adopting new technologies, which can be expensive in some situations.

The construction industry needs regulatory efforts to pursue strategies to recycle and reuse waste products. The lack of effective political institutions and a robust legal environment that encourages, supports, and monitors SWM implementation leads to failures and discourages reusing and recycling efforts (Ahangar et al., 2021; Ruiz et al., 2020; Chen et al., 2019). Regulations play an essential role in supporting the SWM strategies; for instance, Du et al. (2020) argued that the regulatory attributes of SWM substantially contribute to enforcing policies and ensuring sustainable practices. Thus, this study argues that the waste management operations strategy, technological and regulatory characteristics need to be holistically understood to develop a hierarchical framework for assessing the strategic effectiveness of SWM performance in construction.

\subsection{Sustainable waste management strategic effectiveness in construction}

The strategic effectiveness of SWM denotes the ability to define the right objectives, provide guidelines for implementation, and ensure progress toward goals by consistently comparing performance with waste management objectives. In the construction industry, SWM strategies have been developed due to their higher rates of waste generation, severe environmental impacts, and low reusing and recycling rates (Lu et al., 2019; Wu et al., 2019; Xu et al., 2019). Yet, prior studies have concentrated on developing and applying SWM options based on reuse, reduction and recycling principles while paying less attention to evaluating the strategic effectiveness of existing options (Li et al., 2020; Blaisi, 2019; Huang et al., 2018). Chen et al. (2019) noted that policies intended for the strategic effectiveness of construction 
waste management are already in place, and stakeholders' awareness has improved. However, the implementation is still incomplete in practice. Wu et al. (2019) underlined the significance of developing a measurement framework for the strategic effectiveness of SWM. The framework assists policy and decision-makers in improving existing strategies (Ghaffar et al., 2020; Wu et al., 2019; Abarca-Guerrero et al., 2017). Strategic effectiveness attributes enable the accurate assessment and measurement of progress toward recycling and reuse goals and solve the construction industry problems.

Prior studies have been undertaken to find strategic effectiveness attributes (Du et al., 2020; Blaisi, 2019; Ajayi et al., 2015). For instance, in the construction industry, Ajayi et al. (2015) stated that effectiveness is related to employee attitude and the ability to predict waste generation, benchmark implementation performance, and set targets during planning. Chen et al. (2019) argued that understanding the operational strategy process under different situations is critical for attaining better strategic effectiveness. However, Blaisi (2019) highlighted that effective operational strategies are not enough when collaborative decision making, sharing information and effective communication among practitioners do not exist. Furthermore, Du et al. (2020) emphasized that policy and regulatory attributes, such as public participation, incentives, and government regulations, play a significant role in achieving strategic effectiveness. A hierarchical framework among the attributes supports identifying reuse and recycling options and policy initiatives. Kabirifar et al. (2020) argued that SWM's strategic effectiveness attributes need to be identified and structured to effectively manage waste reusing and recycling or responsible disposal. Therefore, this study aspires to provide a framework for the strategic effectiveness attributes of SWM in construction, thereby enhancing the knowledge of decision-makers and providing insightful implications for construction firms.

\subsection{Proposed Method}

This study involves validating SWM strategic effectiveness attributes and structuring a hierarchical assessment framework under uncertainties. Prior studies have presented the attributes and practices that lead to SWM in construction (Aslam et al. 2020; Bao and Lu 2020; Du et al. 2020). The attributes are a prerequisite for developing an assessment framework. However, previous studies on construction waste management lack a multilevel model that depicts the interrelationships among the attributes into a hierarchical framework that finds and ranks the optimal drivers for practical improvement (Alnajem et al., 2021; Kabirifar et al., 2020). The systematic classification and categorization of the measurement attributes are needed. Also, prior studies have neglected to carry out validation and have failed to consider the uncertainties from linguistic preferences for developing a measurement framework ( $\mathrm{Wu}$ et al., 2019; Yuan et al., 2012). Hence, this study applied a hybrid method of fuzzy set theory to address the uncertainties related to experts' linguistic preferences, FDM, to identify a set of valid criteria. The Delphi method requires consensus among experts involved in particular complex problems. The experts share and exchange opinions and preferences from their experience and knowledge until reaching a general agreement. This method has a weakness in dealing with expert linguistic preference uncertainty; thus, fuzzy set theory is combined with the Delphi method to overcome this weakness (Sadeghi et al., 2021; Tseng et al., 2019). Combining fuzzy set theory and the traditional Delphi methods means less time is required for data collection and fewer interviews are needed; this advantage improves the method's efficiency and provides accurate and thorough information (Tseng et al., 2021; Tsai et al., 2020). 
FISM is used to investigate the interrelationships among attributes and establish a hierarchical framework. In addition, prior studies lack qualitative information and measurements of attributes related to perceptions and cognition; hence, BWM is applied to generate reliable results and consistent comparisons (Rezaei, 2015; Zhang et al., 2017). As a result of the FISM technique, a complex set of attributes is broken down into sub-aspects, and a multilevel structure is built to show how various aspects interact. The FISM was used to consider the interrelationships among attributes and establish a hierarchical framework (Negash et al., 2021). BWM is employed to determine the weight of criteria to justify effective and ineffective criteria (Zhang et al., 2017; Rezaei, 2015).

\subsection{Proposed Measures}

This study performed a content analysis on SWM strategic effectiveness attributes to propose 75 criteria from the literature (see Appendix A). After two rounds of Delphi assessment, 28 criteria are validated and discussed in this section (Figure 1).

The policy and regulatory support represent the availability of effective political institutions and a robust legal environment that encourages, supports, and monitors SWM implementation (Du et al., 2020; Li et al., 2020; Chen et al., 2019). Providing and adopting relevant laws (C1), which involve all the necessary elements, such as different stakeholder goals, available resources, and existing problems, are significant and supportive criteria of effectiveness (Galves Martoz et al., 2018; Um et al. 2018; Ruiz et al., 2020). The level of compliance of stakeholders (C2) with the national plans and sustainability laws also indicates the effectiveness of the existing strategies (Ajayi et al., 2017; Esa et al., 2017). Public awareness (C3) measures waste management strategies attains recycle and reuse goals (Du et al., 2020; Esa et al., 2017). The availability of incentives (C4) to encourage 3Rs efforts is needed to stimulate the effectiveness of strategies and prevent illegal waste dumping, which motivates contractors to adopt sustainable strategies (Yuan, 2013; Jin et al., 2019; Li et al., 2020). Implementing high taxes and fines (C5) on illegal waste dumping and taxes on primary virgin materials urges construction project stakeholders to adopt responsible waste management techniques and to use secondary materials (Chen et al., 2019; Li et al., 2020; Du et al., 2020). A lack of public support for SWM policies and objections harms strategic effectiveness. Social acceptance (C6) is essential for assessing the strategic effectiveness of SWM (Ghaffar et al., 2020; He \& Yuan, 2020; Abarca-Guerrero et al., 2017). In addition, national action plans (C7) that clarify goals, targets, and visions to move toward SWM promote 3R's effectiveness and indicate political institutions' maturity and commitment toward sustainability (Jin et al., 2019; Abarca-Guerrero et al., 2017). Virtual mockup (C8) is used for preliminary analysis of construction building systems, comparing different methods and materials, and predicting the potential waste related to each option. These building information modeling-based processes effectively prevent waste generation from the first stage of planning and design (Li et al., 2020; Jin et al., 2019; Won \& Cheng, 2017). 


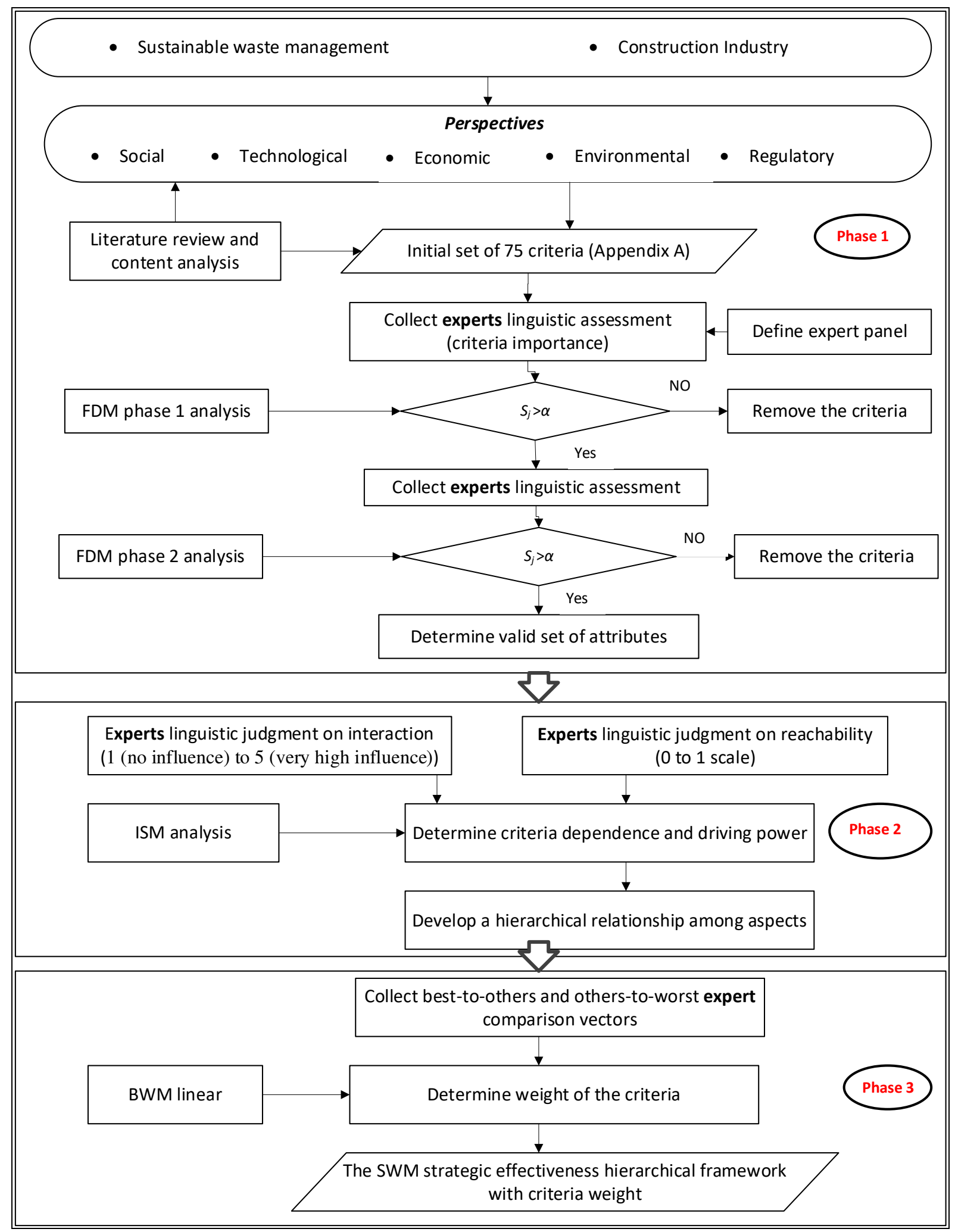

Figure 1. Conceptual framework

Site waste management performance is related to builders, construction teams, and design practitioners' capacity to use recycled waste products, practice waste reduction, and salvage and reuse existing materials. Site waste management is connected to firms' social environment, such as practices, behaviors, norms, and stakeholder values (Aslam et al., 2020; Jin et al., 2019; Abarca-Guerrero et al., 2017). Recycling rate (C9) provides valuable 
information and enables decision-makers to understand recycling effectiveness, performance, and feedback from stakeholders to improve recycling in future activities (Ruiz et al., 2020; Hao et al., 2019; Marrero et al., 2017). The adoption of modern construction methods (C10), such as sustainable construction, modular design, prefabrication, and off-site construction, effectively reduces construction waste (Ruiz et al., 2020; Won \& Cheng, 2017; Ajayi et al., 2017). Employees' waste management knowledge (C11) and water and land usage (C12) indicate the degree of favorable sustainable practices among waste management operators, which effectively evaluates and achieves progress toward SWM (Jin et al., 2019; Wu et al., 2019). Waste generation is associated with human behavior and activities. The reuse rate (C13) signifies the level of waste minimization commitment mitigating site waste production and the achievement of waste reduction targets (Yuan, 2013; Ajayi et al., 2017; Borghi et al., 2018). Building eco-design (C15) or green design assists in preventing waste generation during the transport of raw materials, construction and demolition processes, and the end of life of construction materials (Abarca-Guerrero et al., 2017; Esa et al., 2017). Construction waste reduction and management are achieved by formulating site waste management practices (C14), which reduce waste generation during site operation from design changes and bad practices (Galves Martoz et al., 2018; Jin et al., 2019). The rate of waste reduction (C16) significantly affects the motivation of project stakeholders, and the efficient reduction in waste during the design and construction stages increases stakeholder satisfaction (Hao et al., 2019; Borghi et al., 2018; Ding et al., 2018). The impact of illegal dumping on the social image (C17) constrains the behavior of contractors and individuals and regulates waste generation and management practices (Du et al., 2020; Ghaffar et al., 2020; Abarca-Guerrero et al., 2017).

The technological support relates the measurement criteria related to firms' operations, degree of technology usage, innovations, and practical decisions that influence the firms' effectiveness (Li et al., 2020; Ruiz et al., 2020; Ajayi et al., 2017). The economic support concerns the cost and benefits attributes of SWM strategic effectiveness that bring financial gains and reduce costs while decoupling social and environmental hazards (Kabirifar et al., 2020; Hao et al., 2019; Galves Martoz et al., 2018). The availability of treatment facilities (C18) for waste management, such as collection, recycling, prefabrication, and sorting facilities, reflects the level of maturity of firms' SWM strategies (Esa et al., 2017; Galves Martoz et al., 2018; Kabirifar et al., 2020). Building and maintaining mutual coordination (C19) among stakeholders, such as shared learning, teamwork and trust, enhance management's success and produces effective outcomes (Aslam et al., 2020; Abarca-Guerrero et al., 2017). Recycled market maturity (C20) plays a substantial role in assessing the effectiveness of management strategies, as it encompasses the demand and quality of recycled products and the suitability of the technology and approaches used (Won \& Cheng, 2017, Jin et al., 2019; He \& Yuan, 2020).

Waste management operational strategy refers to the waste prevention, minimization, recycling and reusing measures that evaluate construction projects' performance; this is beneficial to tracking and tackling the environmental impacts (Borghi et al. 2018; Kabirifar et al., 2020; Perteghella et al., 2020). The operational and overhead costs (C21) of waste management, such as collection, transportation, sorting, and treatment costs, affect the implementation of waste management strategies; the higher the costs are, the less effective the waste management strategies (Ruiz et al., 2020; Chen et al., 2019; Abarca-Guerrero et al., 2017). The effectiveness of existing SWM methods is linked with construction waste landfills. The amount of land space saved (C22), reducing the amount of waste being added to landfills, is a crucial indicator of SWM and reflects a reduction in the demand for new landfills and the diversion of waste into reuse or recycling purposes (Perteghella et al., 2020; Borghi et al. 2018; 
Jin et al. 2017). The extent of air pollution (C23) and noise pollution (C25) are significant environmental performance indicators. They include waste from dust, machinery noise, dumping in virgin land areas, blocking rainwater channels, contaminating underground water, and becoming a breeding ground for mosquitos (Kabirifar et al., 2020; Borghi et al., 2018; Yuan, 2013). The criteria include the considerations given to the implications for occupational safety measures (C24), which refer to assessing the stakeholders' awareness and knowledge of the impacts of construction waste management methods on health (Kabirifar et al., 2020; Perteghella et al., 2020; Borghi et al., 2018). Hiring a green subcontractor (C26) with sustainability experience enables green material utilization and implementation of procedures that promote strategic effectiveness (Esa et al., 2017). Building information modeling-based planning (C27) is an innovative and easy technique to attain effective recycling and reuse. It combines building information modeling and management task schedules to provide information about the task sequences and land area required for waste management operations. Public health safety measures (C28) are a significant effectiveness attribute and are beneficial for conducting daily operations and attaining effective site waste management (Ajayi et al., 2017).

\section{Method}

\subsection{Data Collection}

Based on the purpose of this study and convenient sampling methods, this study contacted 30 experts from the construction industry. The experts are from Somaliland and were selected evenly from private construction firms, related government sectors, and the academic sector. The selection was based on their current role in their organization's strategic planning and relevant experience in construction and demolition waste management. Out of the 30 contacted, 24 responded, and 18 agreed to participate in this study. The participant profile includes 12 civil engineers, three architects, and three chief executive officers, each with a minimum experience of 10 years. The experts participated in two rounds of Delphi assessment, two rounds of FISM interviews, and a BWM criteria weight valuation.

\subsection{Analytical Methods}

This section presents the FDM, FISM and BWM research methods and explains the steps used for data analysis.

\subsubsection{Fuzzy Delphi method}

This study involved two Delphi rounds and adopted the FDM procedures applied by (Tseng et al., 2021; Negash \& Hassan, 2020). The 18 experts evaluated the initial set of 75 criteria proposed based on the literature and submitted their opinions in linguistic terms, as shown in Table 1, which were then transformed into fuzzy triangular numbers (TFNs). Thus, attribute $x$ assessed by expert $y$ was transformed as $j=\left(a_{x y} ; b_{x y} ; c_{x y}\right), x=1,2,3, \ldots, n ; y=$ $1,2,3, \ldots, m$. The TFNs were aggregated using the geometric mean to establish the fuzzy weight $\left(w_{j}\right)$ of all criteria:

$$
\mathrm{w}_{\mathrm{j}}=\left\{a_{y}=\min \left(a_{x y}\right), b_{y}=\left(\prod_{1}^{n} b_{x y}\right)^{1 / n}, \text { and } c_{y}=\max \left(c_{x y}\right)\right\}
$$

where $w_{j}$ is the evaluation score of criteria $j, y$ is the expert rated score of criteria $j, n$ is the 401 
Table 1. FDM transformation table of linguistic terms

\begin{tabular}{lll}
\hline Linguistic term & Meaning (Importance) & Corresponding TFN \\
\hline VH & Very High & $(0.75,1.0,1.0)$ \\
H & High & $(0.5,0.75,1.0)$ \\
L & Low & $(0.25,0.50,0.75)$ \\
VL & Very Low & $(0.0,0.25,0.50)$ \\
$\mathrm{NI}$ & No & $(0.0,0.0,0.25)$ \\
\hline
\end{tabular}

403

404

405

406

407

408

409

410

411

412

413

414

415

416

417

418

419

420

421

422

423

424

425

426

The aggregated fuzzy weights of each criterion are defuzzified $\left(S_{j}\right)$, and a threshold $(\alpha)$ is set for screening out the nonsignificant criteria. If $S_{j} \geq \alpha$, then the $j^{\text {th }}$ criterion is accepted; if $S_{j}$ $<\alpha$, then the $j^{\text {th }}$ criterion is rejected, and it will be deleted. In this situation, $\alpha$ is the average of the defuzzified weights.

$$
\begin{aligned}
& S_{j}=\frac{\sum w_{j}}{3} j=1,2,3 \ldots \ldots m \\
& \alpha=\frac{\sum S_{j}}{n}, x=1,2,3 \ldots \ldots n
\end{aligned}
$$

\subsubsection{Fuzzy interpretive structural modeling}

The 18 experts were then asked to fill out two questionnaires to evaluate the interaction and reachability between criteria $d_{i}$ and $d_{j}, i, j=1,2, \cdots, n$ using linguistic terms (Table 2 ). The response from the $y^{\text {th }}$ expert $\left(D_{i j}^{y}\right)$ is presented as follows:

$$
D_{i j}^{y}=\left[\begin{array}{ccccc} 
& d_{1}^{y} & d_{2}^{y} & \cdots & d_{j}^{y} \\
d_{1}^{y} & d_{11}^{y} & d_{12}^{y} & \cdots & d_{1 n}^{y} \\
d_{2}^{y} & d_{21}^{y} & d_{22}^{y} & \cdots & d_{2 n}^{y} \\
\vdots & \vdots & \vdots & \ddots & \vdots \\
d_{i}^{y} & d_{n 1}^{y} & d_{n 2}^{y} & \cdots & d_{n n}^{y}
\end{array}\right]
$$

Table 2 was used to convert the experts' linguistic terms into their corresponding TFN values. Therefore, $D_{i j}^{y}$ is also rewritten as $\left[x_{i j}^{y}, y_{i j}^{y}, z_{i j}^{y}\right]_{n x n}$.

Table 2. FISM transformation table of linguistic terms

\begin{tabular}{cll}
\hline Linguistic term & Meaning & Corresponding TFN \\
\hline $\mathrm{NI}$ & No influence/importance & $(0.00,0.10,0.30)$ \\
$\mathrm{VL}$ & Very low influence/importance & $(0.10,0.30,0.50)$ \\
$\mathrm{E}$ & Equal influence/importance & $(0.30,0.50,0.70)$ \\
$\mathrm{HI}$ & High influence/importance & $(0.50,0.70,0.90)$ \\
$\mathrm{VH}$ & Very high influence/importance & $(0.70,0.90,1.00)$ \\
\hline
\end{tabular}

Then, the defuzzification process is employed. The equation below represents the normalization of TFNs:

$$
\left[x_{i j}^{y}, y_{i j}^{y}, z_{i j}^{y}\right]=\left[\frac{\left(x_{i j}^{y}-\min x_{i j}^{y}\right)}{\alpha}, \frac{\left(y_{i j}^{y}-\min y_{i j}^{y}\right)}{\alpha}, \frac{\left(z_{i j}^{y}-\min z_{i j}^{y}\right)}{\alpha}\right]
$$

where $\alpha=\max z_{i j}^{y}-\min x_{i j}^{y}$. The left $L_{i j}^{y}$ and right $R_{i j}^{y}$ normalized values are computed:

$$
\begin{gathered}
L_{i j}^{y}=\bar{y}_{i j}^{y} /\left(1+\bar{y}_{i j}^{y}-\bar{x}_{i j}^{y}\right), \\
R_{i j}^{y}=\bar{z}_{i j}^{y} /\left(1+\bar{z}_{i j}^{y}-\bar{y}_{i j}^{y}\right)
\end{gathered}
$$

The crisp normalized values $\theta_{i j}^{y}$ of each expert are generated:

$$
\theta_{i j}^{y}=\left[L_{i j}^{y}\left(1-L_{i j}^{y}\right)+\left(R_{i j}^{y}\right)^{2}\right] /\left(1+R_{i j}^{y}-L_{i j}^{y}\right)
$$


The aggregated matrix is calculated by integrating the crisp values:

$$
A_{i j}^{y}=\sum_{i, j=1}^{n}\left(\theta_{i j}^{y}\right) / y=\left[a_{i j}\right]_{n x n}
$$

In the second interview, the experts rated the relationship probability between $C_{i}$ and $C_{j}$ as shown below:

$$
P_{i j}^{y}=\left[\begin{array}{ccccc} 
& p_{1}^{y} & p_{2}^{y} & \ldots & p_{j}^{y} \\
p_{1}^{y} & p_{11}^{y} & p_{12}^{y} & \ldots & p_{1 j}^{y} \\
p_{2}^{y} & p_{21}^{y} & p_{22}^{y} & \ldots & p_{2 j}^{y} \\
\ldots & \cdots & \cdots & \ldots & \ldots \\
p_{i}^{y} & p_{i 1}^{y} & p_{i 2}^{y} & & p_{i j}^{y}
\end{array}\right]=\left[p_{i j}\right]_{n x n^{\prime}} 0 \leq p_{i j} \leq 1
$$

Then, the expected matrix $X$ is computed as follows:

$$
X=\left[a_{i j}\right]_{n \times n} x\left[p_{i j}\right]_{n \times n}=\left[x_{i j}\right]_{n \times n}
$$

Subsequently, the driving $\alpha$ and dependence $\beta$ powers are computed, and the causeeffect diagram is plotted using the $\alpha$ value as the horizontal axis and the $\beta$ value as its vertical axes (Govindan et al., 2012; Negash et al., 2021).

$$
\begin{aligned}
& \alpha=\left[\sum_{i=1}^{n} c_{i j}\right]_{n \times 1}=\left[c_{i}^{\alpha}\right]_{n \times 1} \\
& \beta=\left[\sum_{i=1}^{n} c_{i j}\right]_{1 \times n}=\left[c_{j}^{\beta}\right]_{1 \times n}
\end{aligned}
$$

The cause-effect diagram is divided into four quadrants; criteria with the strongest driving and dependence powers are termed linkage criteria and lie in quadrant $I$. The dependent criteria lie in quadrant $I$, and these have weaker driving power with higher dependence power. Quadrant III has both weaker driving and dependence powers, and these criteria are called autonomous. Last, the independent criteria have higher driving power but weaker dependence power and lie in Quadrant IV.

Binary reachability and antecedent matrix by established threshold $\alpha^{y}$ and $\beta^{y}$ values:

$$
\alpha^{y}=\left[\sum_{i=1}^{n} c_{i j}\right]_{n x 1}
$$

If $c_{i j} \geq \alpha^{y}$, then the reachability scale is considered to be 1 ; otherwise, it is 0 .

$$
\beta^{y}=\left[\sum_{i=1}^{n} c_{i j}\right]_{1 \times n}
$$

If $c_{i j} \geq \beta^{y}$, then the antecedent scale is considered to be 1 ; otherwise, it is 0 . Consequently, the binary intersection set $S$ is found:

$$
\begin{gathered}
\alpha^{y}=1, R=\left\{C_{1}, C_{2}, C_{3}, \cdots C_{n}\right\} ; \beta^{y}=1, A=\left\{C_{1}, C_{2}, C_{3}, \cdots C_{n}\right\} \\
S=R \cap A
\end{gathered}
$$

Finally, the intersection set frequency $(G)$ of each criterion is obtained, and the criteria with the same $G$ value will be arranged into one level.

\subsubsection{Best-worst method}

$$
\mathrm{G}=\left[\sum_{\mathrm{j}=1}^{\mathrm{n}} \mathrm{s}_{\mathrm{ij}}\right]_{1 \times \mathrm{n}}=\left[\mathrm{s}_{\mathrm{j}}\right]_{1 \times \mathrm{n}}
$$

The BWM is an approach to prioritize the weights of the criteria for a group of decisionmakers. In the BWM, the criteria weights are computed by pairwise comparison others-toworst; these increase the reliability of the comparison (Zhang et al., 2017; Rezaei, 2015). The best and worst criteria are determined from the FDM result. This study applied the BWM and determined the weight of criteria to justify effective and ineffective attributes.

$$
A_{B n}=\left(x_{B 1}, x_{B 2}, x_{B 3} \ldots \ldots x_{B n}\right)
$$

where $A_{B n}$ denotes the best-to-others vector and $x_{B n}=\left(a_{x y} ; b_{x y} ; c_{x y}\right)$ denotes the preference of effective attribute $B$ over attribute $\mathrm{n}^{\text {th }}$.

$$
\mathrm{A}_{m W}=\left(x_{1 W}, x_{2 W}, x_{3 W} \ldots \ldots x_{m W}\right)^{T}
$$


where $A_{m W}$ denotes the others-to-worst vector and $x_{m W}=\left(a_{x y} ; b_{x y} ; c_{x y}\right)$ shows the preference of ineffective attribute $W$ over the $m^{\text {th }}$ attribute.

This study assumed a BWM linear model and minimized the maximum among the set of $\left\{\left|\frac{w_{B}}{w_{n}}\right|,\left|\frac{w_{m}}{w_{W}}\right|\right\}$. Hence, the maximum absolute difference among all sets of $m$ criteria should be minimized.

$$
\text { Maximum absolute difference }=\left(\left|\alpha_{n}-x_{B n}\right|,\left|\beta_{m}-x_{m W}\right|\right)
$$

where $\left(\alpha_{n}, \beta_{m}\right)$ is computed as $\alpha_{n}=\left(\frac{w_{B}}{w_{n}}\right)$ and $\beta_{m}=\left(\frac{w_{m}}{w_{W}}\right)$ and arranged into a min-max model.

$$
\text { Model } 1\left\{\begin{array}{c}
\min \max (n)\left\{\left|\alpha_{n}-x_{B n}\right|,\left|\beta_{m}-x_{m W}\right|\right\} \\
\sum_{n} w_{n}^{*}=1
\end{array}\right\}
$$

Model 1 was transformed into the linear programming model as follows (Rezaei, 2016).

$$
\text { Model } 2\left\{\begin{array}{c}
\text { for min } \varepsilon \\
\left|w_{B}-w_{n} x_{B n}\right| \leq \varepsilon^{L},\left|w_{m}-w_{W} x_{m W}\right| \leq \varepsilon^{L} \\
\sum_{n=0} w_{n}^{*}=1, w_{n}^{*} \geq 0
\end{array}\right\}
$$

Hence, $\left(w_{1}^{*}, w_{2}^{*}, w_{3}^{*}, w_{4 \ldots \ldots \ldots . .,}^{*} w_{n}^{*}\right)$ at the ideal weight value of $\varepsilon^{L *}$ are acquired. $\varepsilon^{L *}$ is $\in(0,1)$, where values close to 0 represent higher consistency, while those values close to 1 indicate inconsistency.

\section{Results}

This section reports the case background in the Somaliland construction industry and the results from the proposed analytical methods. Thus, the valid set of attributes is presented, the hierarchical framework is provided, and the contextual relationship is identified.

\subsection{Case Background}

Somaliland construction industry is a booming sector and contributes significantly to the economic progress; nonetheless, there is overall ineffectiveness of performance from the builders, construction teams, and design practitioners' ability to use recycled waste products and waste management process (Omar et al. 2020; Negash \& Hassan, 2020; World Bank, 2015). In Somaliland, there is a mounting waste generation rate caused by the increased construction activities by the population growth, urbanization rates, GDP growth and absence of robust legal attributes. This brings environmental and social burdens such as land space occupation, raw material over usage, energy consumption, and gas emissions. Due to the increasing concerns of CDW waste, public and private institutions need to formulate, implement, and ensure SWM strategic effectiveness to reduce the environmental and social burden and mitigate resource depletion by construction activities.

In Somaliland, there are low waste collection services and incapability of transforming waste materials into valuable products; this situation resulted in severe consequences to the social wellbeing, environment and economic losses, which need to be addressed (Di Bella \& Vaccari, 2014). There are potentially well-suited SWM strategies proposed and applied during construction activities' early phases. However, most of them are not successful at the implementation stage due to weak performance measurement and lack of a framework for evaluating SWM strategic effectiveness. The outcome of SWM strategies is not satisfactory due to uncertainties in assessing and tracking the strategic effectiveness during the planning phase. Although the demand and awareness for better SWM exist, the underperformance and reduced effectiveness can be traced back to the lack of considerations to the principal strategic effectiveness attributes that can dictate the success of the strategies and reaching the recycle 
and reuse goals. SWM strategic effectiveness attributes framework enables continuous and accurate assessment and measures the progress towards recycling and reuse goals to solve the industry problems. Therefore, this study aspires to provide a framework of SWM strategic effectiveness attributes, thereby enhancing knowledge of decision-makers and giving insightful implications for increasing the SWM strategic effectiveness of construction firms.

\subsection{Measures Validity}

The initially proposed set of 75 criteria is shown in Appendix A. Applying Equations 1-3, the threshold was found to be 0.591 , and 51 criteria were found to be larger than the threshold and, thus, were accepted. Appendix B contains the result of the first-round Delphi and presents the initial criteria and acceptance threshold weights. The accepted criteria were organized and forwarded for the second-round assessment (see Appendix C). The FDM procedure was repeated, and the final set of valid SWM effectiveness measures was generated. The threshold for second-round acceptance was found to be 0.512 , and 28 criteria achieved the final consensus among experts. They were identified as valid measures for strategic effectiveness (see Appendices D). The valid set of attributes and their weights are presented in Table 3.

Table 3. SWM strategy validated measures ( ${ }^{*}$ Threshold value $=0.512$ )

\begin{tabular}{lll}
\hline Criterion & Weight \\
\hline C1 & Relevant laws & 0.797 \\
C2 & Level of compliance & 0.773 \\
C3 & Public awareness & 0.757 \\
C4 & Incentives & 0.668 \\
C5 & Taxes and fines & 0.665 \\
C6 & Social acceptance & 0.644 \\
C7 & National plans & 0.642 \\
C8 & Virtual mockup process & 0.635 \\
C9 & Recycling rate & 0.797 \\
C10 & Adaptation of modern construction & 0.789 \\
C11 & Laborer's waste management knowledge & 0.789 \\
C12 & Water and land usage & 0.780 \\
C13 & Reused waste & 0.780 \\
C14 & Site waste management effectiveness & 0.757 \\
C15 & Eco-designing & 0.661 \\
C16 & Waste reduction rate & 0.633 \\
C17 & Social image & 0.616 \\
C18 & Treatment facilities & 0.806 \\
C19 & Mutual coordination & 0.648 \\
C20 & Recycled market maturity & 0.648 \\
C21 & Operational and overhead costs mitigation plans & 0.806 \\
C22 & Landfill spaces saving measures & 0.797 \\
C23 & Air pollution control plans & 0.780 \\
C24 & Occupational safety measures & 0.780 \\
C25 & Noise pollution control plans & 0.773 \\
\hline
\end{tabular}




\begin{tabular}{lll}
\hline C26 & Subcontractor green rating systems & 0.658 \\
C27 & Building information modeling -based phase planning & 0.642 \\
C28 & Public health safety measures & 0.597 \\
\hline
\end{tabular}

\subsection{Attributes hierarchical relationship and ranking}

Experts were asked to fill out two questionnaires based on the 28 validated measures to assess the interactions between the criteria and the reachability level. First, the experts used a fuzzy scale ranging from 1 (no influence) to 5 (very high influence) to determine the interactions. Responses were transferred into the equivalent TFNs shown in Table 2. Second, experts completed the assessment based on the probability that one criterion reaches another using a scale ranging from 0 to 1, where 1 represents 100\% reachability. Using Equations 4-7, the experts' decisions were combined to form the integrated reachability matrix shown in Table 4. Using Equations 8-9, driving and dependence powers are computed, and Figure 2 is generated based on the 28 valid criteria. The results show that $\mathrm{C} 9, \mathrm{C} 12, \mathrm{C} 13, \mathrm{C} 14, \mathrm{C} 15, \mathrm{C} 16$, $\mathrm{C} 22, \mathrm{C} 23, \mathrm{C} 25$, and C28 belong to quadrant I and are linkage criteria; C4, C7, C10, C13, C17, and C24 belong to quadrant II and are dependent criteria; C8, C18, C19, C20 and C27 belong to quadrant III and are autonomous criteria; and $\mathrm{C} 1, \mathrm{C} 2, \mathrm{C} 3$, and $\mathrm{C} 6$ belong to quadrant IV and are independent criteria. The linkage criteria are the most crucial with higher driving and dependence power, which means that strategic effectiveness can be evaluated accurately by their level of performance. 
Table 4. Integrated reachability matrix

\begin{tabular}{|c|c|c|c|c|c|c|c|c|c|c|c|c|c|c|c|}
\hline & $\mathrm{C} 1$ & $\mathrm{C} 2$ & $\mathrm{C} 3$ & $\mathrm{C} 4$ & $\mathrm{C} 5$ & $\mathrm{C} 6$ & $\mathrm{C} 7$ & $\mathrm{C} 8$ & C9 & $\mathrm{C} 10$ & C11 & $\mathrm{C} 12$ & $\mathrm{C} 13$ & C14 & C15 \\
\hline $\mathrm{C} 1$ & 4.667 & 5.297 & 6.560 & 5.686 & 5.753 & 4.819 & 6.538 & 6.053 & 5.886 & 4.962 & 5.428 & 5.534 & 4.115 & 6.259 & 5.494 \\
\hline C2 & 5.385 & 6.255 & 7.490 & 6.435 & 6.552 & 5.736 & 7.528 & 6.918 & 6.806 & 5.704 & 6.174 & 6.410 & 4.650 & 7.226 & 6.325 \\
\hline C3 & 5.460 & 6.259 & 7.440 & 6.419 & 6.571 & 5.446 & 7.497 & 6.847 & 6.663 & 5.582 & 6.186 & 6.336 & 4.598 & 7.255 & 6.313 \\
\hline C4 & 3.875 & 4.692 & 5.859 & 5.145 & 5.112 & 4.344 & 5.862 & 5.373 & 5.247 & 4.679 & 4.824 & 4.952 & 3.667 & 5.379 & 4.997 \\
\hline C5 & 4.150 & 4.829 & 6.065 & 5.013 & 5.094 & 4.566 & 6.074 & 5.480 & 5.348 & 4.604 & 4.803 & 4.961 & 3.729 & 5.789 & 5.112 \\
\hline C6 & 5.585 & 6.483 & 7.826 & 6.667 & 6.909 & 5.554 & 7.713 & 7.225 & 7.120 & 6.159 & 6.480 & 6.702 & 4.909 & 7.492 & 6.741 \\
\hline C7 & 3.988 & 4.698 & 5.809 & 4.783 & 5.135 & 3.962 & 5.790 & 5.456 & 5.247 & 4.523 & 4.769 & 4.861 & 3.617 & 5.462 & 5.000 \\
\hline C8 & 5.842 & 6.658 & 7.507 & 6.954 & 7.082 & 5.588 & 7.486 & 7.080 & 7.165 & 5.919 & 6.635 & 6.749 & 4.992 & 7.400 & 6.591 \\
\hline C9 & 5.985 & 6.780 & 8.095 & 6.984 & 7.304 & 5.679 & 8.039 & 7.542 & 7.411 & 6.299 & 6.814 & 7.001 & 5.164 & 7.685 & 6.984 \\
\hline C10 & 6.759 & 7.584 & 8.905 & 7.819 & 8.009 & 6.645 & 8.866 & 8.297 & 8.229 & 6.868 & 7.569 & 7.816 & 5.772 & 8.573 & 7.577 \\
\hline C11 & 6.606 & 7.342 & 8.845 & 7.865 & 7.895 & 6.670 & 8.835 & 8.271 & 8.132 & 6.960 & 7.583 & 7.803 & 5.717 & 8.514 & 7.476 \\
\hline $\mathrm{C} 12$ & 6.550 & 7.389 & 8.711 & 7.610 & 7.845 & 6.269 & 8.642 & 8.165 & 8.028 & 6.950 & 7.431 & 7.640 & 5.585 & 8.341 & 7.635 \\
\hline $\mathrm{C} 13$ & 5.986 & 6.827 & 8.130 & 7.076 & 7.272 & 5.831 & 8.092 & 7.529 & 7.434 & 6.327 & 6.845 & 7.036 & 5.172 & 7.744 & 7.070 \\
\hline C14 & 6.550 & 7.427 & 8.754 & 7.687 & 7.855 & 6.478 & 8.727 & 8.164 & 7.974 & 6.809 & 7.496 & 7.720 & 5.626 & 8.448 & 7.503 \\
\hline C15 & 6.374 & 7.157 & 8.361 & 7.400 & 7.603 & 6.165 & 8.365 & 7.740 & 7.808 & 6.515 & 7.213 & 7.429 & 5.432 & 8.192 & 7.215 \\
\hline C16 & 6.203 & 6.969 & 8.293 & 7.149 & 7.436 & 5.980 & 8.233 & 7.750 & 7.622 & 6.514 & 7.010 & 7.216 & 5.316 & 7.875 & 7.198 \\
\hline C17 & 6.184 & 6.969 & 8.165 & 7.200 & 7.422 & 5.861 & 8.136 & 7.770 & 7.614 & 6.402 & 7.056 & 7.256 & 5.290 & 7.844 & 6.926 \\
\hline C18 & 5.839 & 6.463 & 7.920 & 6.674 & 6.843 & 5.634 & 7.898 & 7.310 & 7.108 & 5.983 & 6.555 & 6.699 & 4.918 & 7.476 & 6.825 \\
\hline C19 & 6.119 & 7.020 & 7.972 & 7.450 & 7.353 & 5.878 & 7.979 & 7.331 & 7.292 & 6.238 & 7.004 & 7.151 & 5.134 & 7.700 & 7.023 \\
\hline C20 & 6.088 & 6.783 & 7.827 & 7.024 & 7.090 & 5.782 & 7.809 & 7.262 & 7.217 & 6.035 & 6.692 & 6.860 & 5.064 & 7.653 & 6.797 \\
\hline C21 & 6.882 & 7.712 & 8.990 & 7.918 & 8.185 & 6.677 & 8.944 & 8.383 & 8.362 & 7.098 & 7.740 & 7.971 & 5.844 & 8.710 & 7.857 \\
\hline $\mathrm{C} 22$ & 6.021 & 6.849 & 8.129 & 7.039 & 7.384 & 5.813 & 8.087 & 7.631 & 7.525 & 6.380 & 6.963 & 7.139 & 5.281 & 7.790 & 7.062 \\
\hline C23 & 6.328 & 7.161 & 8.452 & 7.378 & 7.663 & 6.005 & 8.336 & 7.957 & 7.804 & 6.795 & 7.263 & 7.426 & 5.479 & 8.043 & 7.403 \\
\hline C24 & 6.736 & 7.541 & 8.841 & 7.868 & 8.120 & 6.395 & 8.768 & 8.424 & 8.267 & 7.012 & 7.650 & 7.850 & 5.828 & 8.480 & 7.483 \\
\hline $\mathrm{C} 25$ & 6.665 & 7.454 & 8.781 & 7.688 & 7.964 & 6.247 & 8.688 & 8.118 & 8.042 & 6.922 & 7.440 & 7.622 & 5.639 & 8.388 & 7.668 \\
\hline C26 & 6.309 & 7.198 & 8.183 & 7.331 & 7.606 & 5.890 & 8.100 & 7.639 & 7.673 & 6.547 & 7.054 & 7.229 & 5.337 & 7.943 & 7.296 \\
\hline $\mathrm{C} 27$ & 6.106 & 7.006 & 7.998 & 7.344 & 7.462 & 5.787 & 7.977 & 7.533 & 7.588 & 6.315 & 6.952 & 7.153 & 5.262 & 7.847 & 7.009 \\
\hline $\mathrm{C} 28$ & 6.278 & 7.141 & 8.269 & 7.429 & 7.663 & 6.086 & 8.235 & 7.795 & 7.804 & 6.643 & 7.289 & 7.501 & 5.537 & 8.089 & 7.110 \\
\hline Driving $\alpha$ & 5.911 & 6.712 & 7.935 & 6.966 & 7.149 & 5.778 & 7.902 & 7.394 & 7.301 & 6.205 & 6.747 & 6.929 & 5.096 & 7.628 & 6.846 \\
\hline
\end{tabular}

Driving $\alpha$ 5.911

\begin{tabular}{|c|c|c|c|c|c|c|c|c|c|c|c|c|c|c|}
\hline & C16 & C17 & $\mathrm{C} 18$ & C19 & C20 & C21 & $\mathrm{C} 22$ & $\mathrm{C} 23$ & C24 & $\mathrm{C} 25$ & C26 & C27 & $\mathrm{C} 28$ & Dependence $\beta$ \\
\hline $\mathrm{C} 1$ & 6.475 & 6.516 & 6.448 & 6.557 & 6.301 & 6.493 & 6.467 & 6.488 & 6.456 & 5.210 & 6.120 & 6.431 & 6.439 & 6.475 \\
\hline $\mathrm{C} 2$ & 7.435 & 7.445 & 7.431 & 7.600 & 6.857 & 7.419 & 7.435 & 7.479 & 7.536 & 6.001 & 7.004 & 7.312 & 7.390 & 7.435 \\
\hline C3 & 7.453 & 7.423 & 7.383 & 7.554 & 7.051 & 7.423 & 7.401 & 7.507 & 7.466 & 6.122 & 6.916 & 7.302 & 7.373 & 7.453 \\
\hline C4 & 5.781 & 5.835 & 5.802 & 5.905 & 5.364 & 5.767 & 5.803 & 5.747 & 5.824 & 4.401 & 5.483 & 5.861 & 5.823 & 5.781 \\
\hline
\end{tabular}




\begin{tabular}{|c|c|c|c|c|c|c|c|c|c|c|c|c|c|c|}
\hline C5 & 6.052 & 5.965 & 6.029 & 6.114 & 5.610 & 6.005 & 6.023 & 6.021 & 6.093 & 4.674 & 5.676 & 6.050 & 5.988 & 6.052 \\
\hline C6 & 7.702 & 7.749 & 7.725 & 7.882 & 6.907 & 7.639 & 7.739 & 7.747 & 7.823 & 5.944 & 6.917 & 7.786 & 7.731 & 7.702 \\
\hline $\mathrm{C7}$ & 5.707 & 5.709 & 5.723 & 5.793 & 5.544 & 5.659 & 5.732 & 5.637 & 5.735 & 4.702 & 5.242 & 5.917 & 5.706 & 5.707 \\
\hline $\mathrm{C} 8$ & 7.380 & 7.570 & 7.388 & 7.537 & 6.556 & 7.397 & 7.410 & 7.519 & 7.486 & 5.697 & 6.450 & 7.264 & 7.480 & 7.380 \\
\hline $\mathrm{C9}$ & 7.956 & 8.060 & 7.868 & 8.110 & 7.261 & 7.998 & 7.968 & 8.055 & 8.025 & 6.321 & 7.166 & 8.105 & 8.026 & 7.956 \\
\hline C10 & 8.759 & 8.899 & 8.773 & 8.956 & 7.891 & 8.810 & 8.794 & 8.894 & 8.892 & 6.840 & 7.898 & 8.755 & 8.836 & 8.759 \\
\hline C11 & 8.709 & 8.836 & 8.760 & 8.925 & 7.932 & 8.766 & 8.750 & 8.838 & 8.833 & 6.699 & 7.913 & 8.720 & 8.785 & 8.709 \\
\hline $\mathrm{C} 12$ & 8.529 & 8.669 & 8.514 & 8.743 & 7.766 & 8.567 & 8.547 & 8.638 & 8.593 & 6.502 & 7.665 & 8.670 & 8.595 & 8.529 \\
\hline $\mathrm{C} 13$ & 7.965 & 8.102 & 7.978 & 8.085 & 7.253 & 8.027 & 8.005 & 8.095 & 8.072 & 6.274 & 7.149 & 8.125 & 8.045 & 7.965 \\
\hline C14 & 8.634 & 8.738 & 8.643 & 8.820 & 7.740 & 8.628 & 8.655 & 8.752 & 8.752 & 6.670 & 7.750 & 8.558 & 8.643 & 8.634 \\
\hline C15 & 8.284 & 8.384 & 8.268 & 8.427 & 7.366 & 8.275 & 8.270 & 8.371 & 8.367 & 6.490 & 7.338 & 8.196 & 8.331 & 8.284 \\
\hline C16 & 8.138 & 8.196 & 8.160 & 8.333 & 7.389 & 8.174 & 8.193 & 8.256 & 8.243 & 6.417 & 7.281 & 8.296 & 8.220 & 8.138 \\
\hline C17 & 8.032 & 8.183 & 8.057 & 8.237 & 7.201 & 8.069 & 8.088 & 8.169 & 8.107 & 6.325 & 7.208 & 8.035 & 8.100 & 8.032 \\
\hline C18 & 7.820 & 7.842 & 7.750 & 7.920 & 7.259 & 7.825 & 7.791 & 7.864 & 7.858 & 6.180 & 7.041 & 7.960 & 7.811 & 7.820 \\
\hline C19 & 7.832 & 8.044 & 7.860 & 8.013 & 7.064 & 7.827 & 7.863 & 7.955 & 7.931 & 6.076 & 6.940 & 7.762 & 7.907 & 7.832 \\
\hline $\mathrm{C} 20$ & 7.714 & 7.842 & 7.695 & 7.854 & 7.052 & 7.748 & 7.719 & 7.900 & 7.805 & 6.053 & 6.852 & 7.707 & 7.714 & 7.714 \\
\hline $\mathrm{C} 21$ & 8.855 & 8.956 & 8.848 & 9.003 & 7.977 & 8.878 & 8.836 & 8.970 & 8.977 & 6.925 & 7.888 & 8.846 & 8.899 & 8.855 \\
\hline $\mathrm{C} 22$ & 7.970 & 8.131 & 7.963 & 8.145 & 7.181 & 7.936 & 8.002 & 8.114 & 8.092 & 6.203 & 7.118 & 8.107 & 8.075 & 7.970 \\
\hline $\mathrm{C} 23$ & 8.243 & 8.388 & 8.264 & 8.449 & 7.507 & 8.295 & 8.276 & 8.288 & 8.399 & 6.245 & 7.404 & 8.453 & 8.323 & 8.243 \\
\hline $\mathrm{C} 24$ & 8.628 & 8.813 & 8.698 & 8.882 & 7.803 & 8.729 & 8.702 & 8.788 & 8.758 & 6.696 & 7.797 & 8.628 & 8.736 & 8.628 \\
\hline $\mathrm{C} 25$ & 8.625 & 8.728 & 8.592 & 8.787 & 7.876 & 8.666 & 8.538 & 8.727 & 8.708 & 6.742 & 7.793 & 8.770 & 8.665 & 8.625 \\
\hline $\mathrm{C} 26$ & 7.988 & 8.173 & 7.975 & 8.191 & 7.280 & 8.023 & 8.017 & 8.124 & 8.146 & 6.105 & 7.101 & 8.149 & 8.089 & 7.988 \\
\hline $\mathrm{C} 27$ & 7.840 & 8.016 & 7.871 & 8.023 & 6.985 & 7.862 & 7.844 & 7.976 & 7.945 & 5.967 & 6.853 & 7.729 & 7.908 & 7.840 \\
\hline $\mathrm{C} 28$ & 8.047 & 8.287 & 8.163 & 8.322 & 7.158 & 8.197 & 8.167 & 8.260 & 8.236 & 6.267 & 7.212 & 8.093 & 8.196 & 8.047 \\
\hline Driving $\alpha$ & 7.806 & 7.911 & 7.808 & 7.970 & 7.112 & 7.825 & 7.823 & 7.899 & 7.898 & 6.098 & 7.042 & 7.842 & 7.851 & 7.806 \\
\hline
\end{tabular}




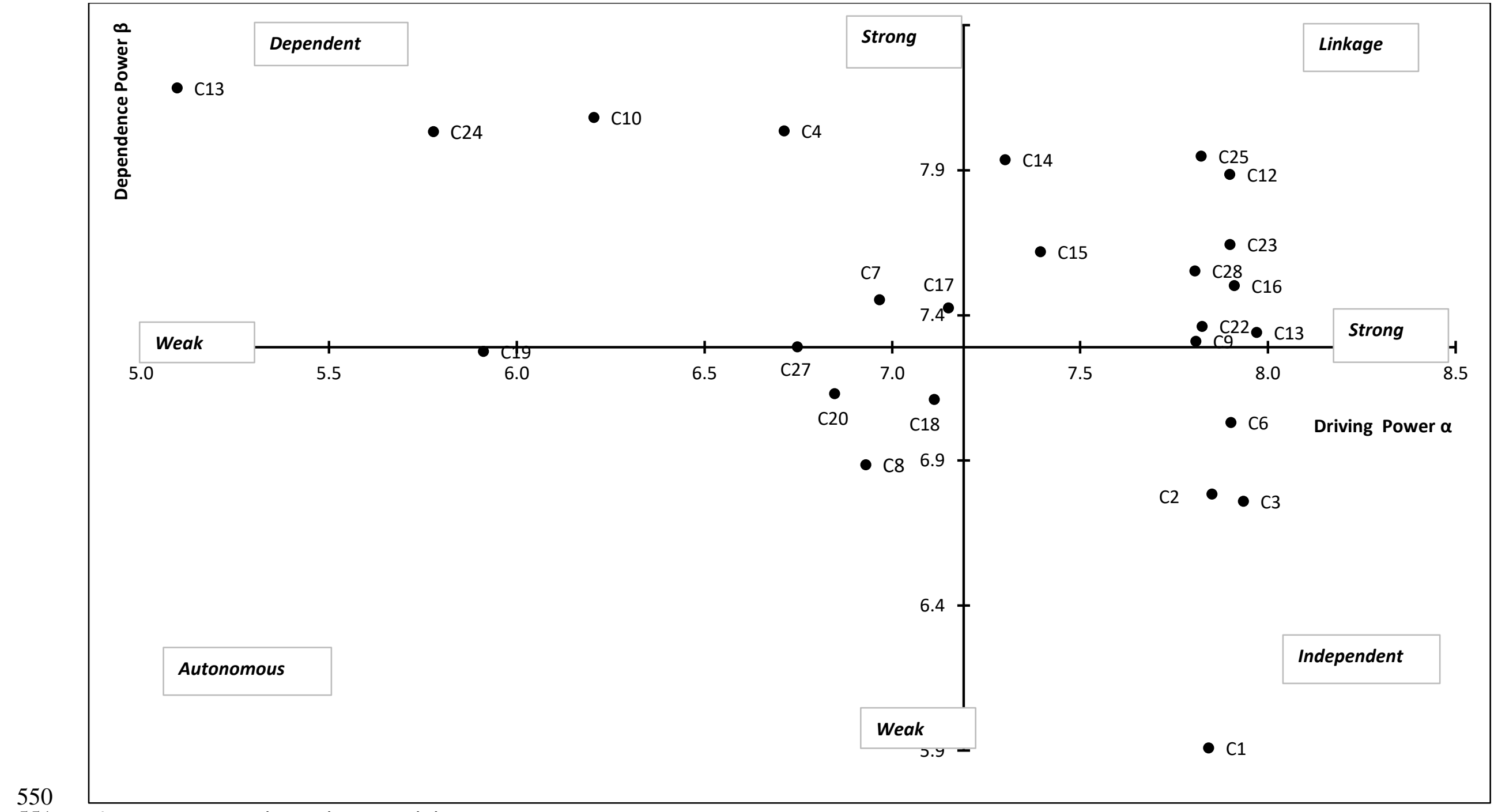


The antecedent and intersection matrices are obtained from the total reachability matrix, as shown in Table 6 and Table 7 (Equations 10-12). The last column of the intersection matrix presents information about the frequency (FQ) and level (L) to structure and group the criteria (Equations 12). The FISM result divides the 28 criteria into six aspects (Table 5). These aspects include waste management operations strategy (A1), site waste management performance (A2), mutual coordination level (A3), facility availability (A4), market performance (A5) and policy and regulatory performance (A6). Furthermore, dependence $(\beta)$ and driving $(\alpha)$ power are calculated by summing the rows and columns of the integrated reachability matrix (see Table 4). The FISM also constructs a multilevel model that depicts the interrelationships among the aspects into a hierarchical framework and ranks the aspects for practical improvement. These levels can be used to assess the strategic effectiveness of SWM. Figure 3 shows criteria weights and their consistency values, and $\varepsilon^{L *}$ values close to 0 represent a high level of consistency. The global weights of all attributes are computed, and ranking is assigned as per attribute.

Table 5. SWM strategy effectiveness attributes

\begin{tabular}{|c|c|c|}
\hline Aspects & Criterion & \\
\hline \multirow[t]{8}{*}{ Policy and regulatory support } & $\mathrm{C} 1$ & Relevant laws \\
\hline & $\mathrm{C} 2$ & Level of compliance \\
\hline & $\mathrm{C} 3$ & Public awareness \\
\hline & $\mathrm{C} 4$ & Incentives \\
\hline & $\mathrm{C} 5$ & Taxes and fines \\
\hline & C6 & Social acceptance \\
\hline & $\mathrm{C7}$ & National plans \\
\hline & $\mathrm{C} 8$ & Virtual mockup process \\
\hline \multirow{9}{*}{$\begin{array}{l}\text { Site waste management } \\
\text { performance }\end{array}$} & C9 & Recycling rate \\
\hline & $\mathrm{C} 10$ & Adaptation of modern construction \\
\hline & C11 & Laborer's waste management knowledge \\
\hline & $\mathrm{C} 12$ & Water and land usage \\
\hline & $\mathrm{C} 13$ & Reused waste \\
\hline & C14 & Site waste management effectiveness \\
\hline & C15 & Eco-designing \\
\hline & C16 & Waste reduction rate \\
\hline & $\mathrm{C} 17$ & Social image \\
\hline \multirow[t]{3}{*}{ Economic and technical support } & C18 & Treatment facilities \\
\hline & C19 & Mutual coordination \\
\hline & $\mathrm{C} 20$ & Recycled market maturity \\
\hline \multirow{8}{*}{$\begin{array}{l}\text { Waste management operations } \\
\text { strategy }\end{array}$} & $\mathrm{C} 21$ & Operational and overhead costs mitigation plans \\
\hline & $\mathrm{C} 22$ & Landfill spaces saving measures \\
\hline & $\mathrm{C} 23$ & Air pollution control plans \\
\hline & $\mathrm{C} 24$ & Occupational safety measures \\
\hline & $\mathrm{C} 25$ & Noise pollution control plans \\
\hline & $\mathrm{C} 26$ & Subcontractor green rating systems \\
\hline & $\mathrm{C} 27$ & BIM-based phase planning \\
\hline & $\mathrm{C} 28$ & Public health safety measures \\
\hline
\end{tabular}


Table 6. Antecedent matrix

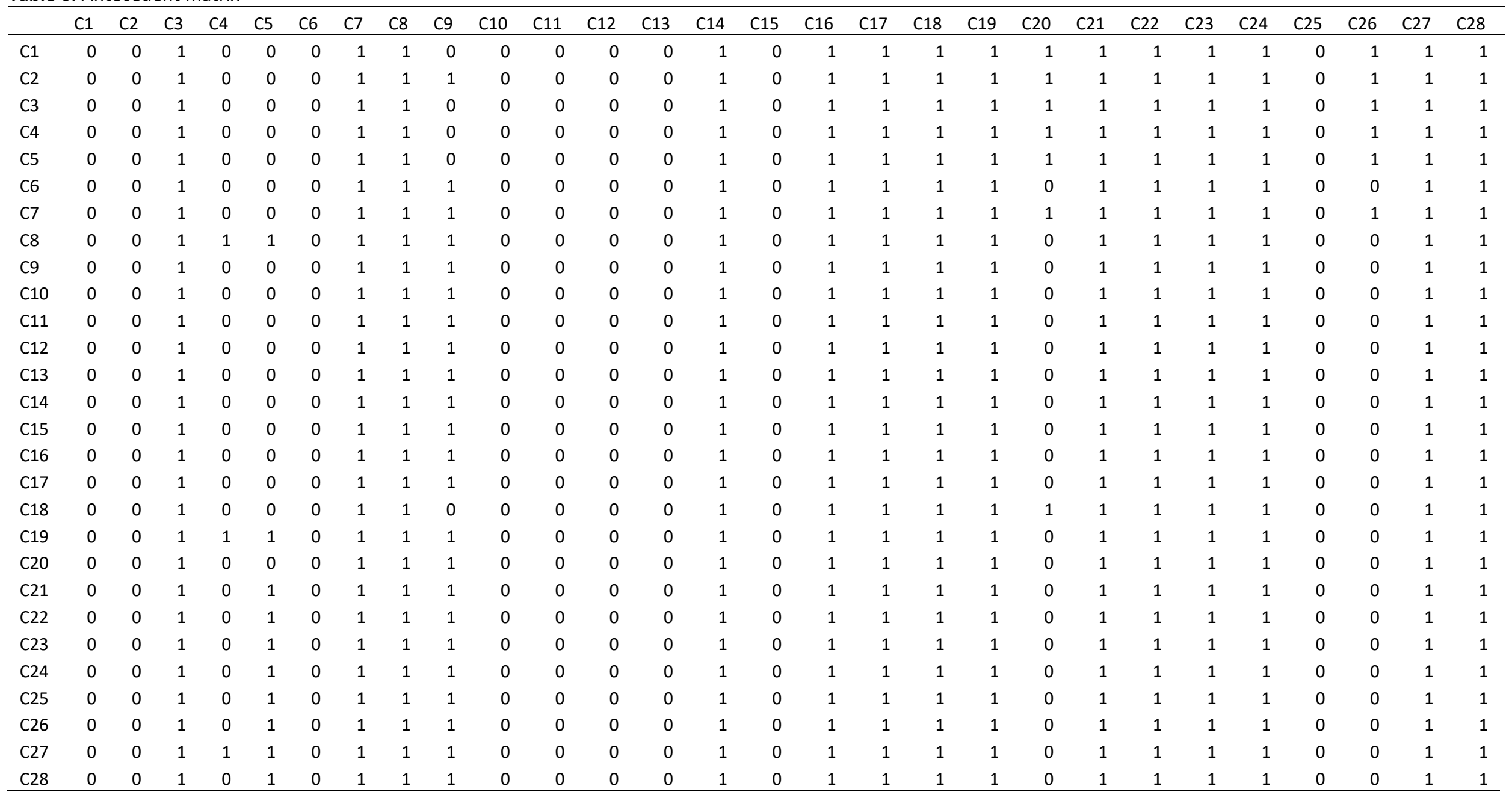


Table 7. Intersection

\begin{tabular}{|c|c|c|c|c|c|c|c|c|c|c|c|c|c|c|c|c|c|c|c|c|c|c|c|c|c|c|c|c|c|c|}
\hline & $\mathrm{C} 1$ & C2 & C3 & C4 & C5 & C6 & C7 & C8 & C9 & $\mathrm{C} 10$ & C11 & $\mathrm{C} 12$ & $\mathrm{C} 13$ & C14 & C15 & C16 & C17 & C18 & C19 & $\mathrm{C} 20$ & C21 & C22 & C23 & C24 & $\mathrm{C} 25$ & C26 & C27 & C28 & $\mathrm{FQ}$ & L \\
\hline $\mathrm{C} 1$ & 0 & 0 & 0 & 0 & 0 & 0 & 0 & 0 & 0 & 0 & 0 & 0 & 0 & 0 & 0 & 0 & 0 & 0 & 0 & 0 & 0 & 0 & 0 & 0 & 0 & 0 & 0 & 0 & 0 & 1 \\
\hline $\mathrm{C} 2$ & 0 & 0 & 0 & 0 & 0 & 0 & 0 & 0 & 0 & 0 & 0 & 0 & 0 & 0 & 0 & 0 & 0 & 0 & 0 & 0 & 0 & 0 & 0 & 0 & 0 & 0 & 0 & 0 & 0 & 1 \\
\hline C3 & 0 & 0 & 0 & 0 & 0 & 0 & 0 & 0 & 0 & 0 & 0 & 0 & 0 & 0 & 0 & 0 & 0 & 0 & 0 & 0 & 0 & 0 & 0 & 0 & 0 & 0 & 0 & 0 & 0 & 1 \\
\hline C4 & 0 & 0 & 0 & 0 & 0 & 0 & 0 & 0 & 0 & 0 & 0 & 0 & 0 & 0 & 0 & 0 & 0 & 0 & 0 & 0 & 0 & 0 & 0 & 0 & 0 & 0 & 0 & 0 & 0 & 1 \\
\hline C5 & 0 & 0 & 0 & 0 & 0 & 0 & 0 & 0 & 0 & 0 & 0 & 0 & 0 & 0 & 0 & 0 & 0 & 0 & 0 & 0 & 0 & 0 & 0 & 0 & 0 & 0 & 0 & 0 & 0 & 1 \\
\hline C6 & 0 & 0 & 0 & 0 & 0 & 0 & 0 & 0 & 0 & 0 & 0 & 0 & 0 & 0 & 0 & 0 & 0 & 0 & 0 & 0 & 0 & 0 & 0 & 0 & 0 & 0 & 0 & 0 & 0 & 1 \\
\hline C7 & 0 & 0 & 0 & 0 & 0 & 0 & 0 & 0 & 0 & 0 & 0 & 0 & 0 & 0 & 0 & 0 & 0 & 0 & 0 & 0 & 0 & 0 & 0 & 0 & 0 & 0 & 0 & 0 & 0 & 1 \\
\hline C8 & 0 & 0 & 0 & 0 & 0 & 0 & 0 & 0 & 0 & 0 & 0 & 0 & 0 & 0 & 0 & 0 & 0 & 0 & 0 & 0 & 0 & 0 & 0 & 0 & 0 & 0 & 0 & 0 & 0 & 1 \\
\hline C9 & 0 & 0 & 1 & 0 & 0 & 0 & 1 & 1 & 1 & 0 & 0 & 0 & 0 & 1 & 0 & 1 & 1 & 1 & 1 & 0 & 1 & 1 & 1 & 1 & 0 & 0 & 1 & 1 & 15 & 5 \\
\hline $\mathrm{C} 10$ & 0 & 0 & 1 & 0 & 0 & 0 & 1 & 1 & 1 & 0 & 0 & 0 & 0 & 1 & 0 & 1 & 1 & 1 & 1 & 0 & 1 & 1 & 1 & 1 & 0 & 0 & 1 & 1 & 15 & 5 \\
\hline $\mathrm{C} 11$ & 0 & 0 & 1 & 0 & 0 & 0 & 1 & 1 & 1 & 0 & 0 & 0 & 0 & 1 & 0 & 1 & 1 & 1 & 1 & 0 & 1 & 1 & 1 & 1 & 0 & 0 & 1 & 1 & 15 & 5 \\
\hline C12 & 0 & 0 & 1 & 0 & 0 & 0 & 1 & 1 & 1 & 0 & 0 & 0 & 0 & 1 & 0 & 1 & 1 & 1 & 1 & 0 & 1 & 1 & 1 & 1 & 0 & 0 & 1 & 1 & 15 & 5 \\
\hline $\mathrm{C} 13$ & 0 & 0 & 1 & 0 & 0 & 0 & 1 & 1 & 1 & 0 & 0 & 0 & 0 & 1 & 0 & 1 & 1 & 1 & 1 & 0 & 1 & 1 & 1 & 1 & 0 & 0 & 1 & 1 & 15 & 5 \\
\hline C14 & 0 & 0 & 1 & 0 & 0 & 0 & 1 & 1 & 1 & 0 & 0 & 0 & 0 & 1 & 0 & 1 & 1 & 1 & 1 & 0 & 1 & 1 & 1 & 1 & 0 & 0 & 1 & 1 & 15 & 5 \\
\hline C15 & 0 & 0 & 1 & 0 & 0 & 0 & 1 & 1 & 1 & 0 & 0 & 0 & 0 & 1 & 0 & 1 & 1 & 1 & 1 & 0 & 1 & 1 & 1 & 1 & 0 & 0 & 1 & 1 & 15 & 5 \\
\hline C16 & 0 & 0 & 1 & 0 & 0 & 0 & 1 & 1 & 1 & 0 & 0 & 0 & 0 & 1 & 0 & 1 & 1 & 1 & 1 & 0 & 1 & 1 & 1 & 1 & 0 & 0 & 1 & 1 & 15 & 5 \\
\hline C17 & 0 & 0 & 1 & 0 & 0 & 0 & 1 & 1 & 1 & 0 & 0 & 0 & 0 & 1 & 0 & 1 & 1 & 1 & 1 & 0 & 1 & 1 & 1 & 1 & 0 & 0 & 1 & 1 & 15 & 5 \\
\hline $\mathrm{C} 18$ & 0 & 0 & 0 & 0 & 0 & 0 & 0 & 0 & 0 & 0 & 0 & 0 & 0 & 0 & 0 & 1 & 0 & 0 & 0 & 1 & 0 & 0 & 0 & 0 & 0 & 0 & 1 & 0 & 3 & 3 \\
\hline C19 & 0 & 0 & 1 & 1 & 1 & 0 & 1 & 0 & 0 & 0 & 0 & 0 & 0 & 1 & 0 & 1 & 1 & 1 & 1 & 0 & 1 & 1 & 1 & 1 & 0 & 0 & 0 & 1 & 14 & 4 \\
\hline C20 & 0 & 0 & 0 & 0 & 0 & 0 & 0 & 0 & 0 & 0 & 0 & 0 & 0 & 1 & 0 & 0 & 0 & 0 & 0 & 0 & 0 & 0 & 1 & 0 & 0 & 0 & 0 & 0 & 2 & 2 \\
\hline C21 & 0 & 0 & 1 & 0 & 1 & 0 & 1 & 1 & 1 & 0 & 0 & 0 & 0 & 1 & 0 & 1 & 1 & 1 & 1 & 0 & 1 & 1 & 1 & 1 & 0 & 0 & 1 & 1 & 16 & 6 \\
\hline $\mathrm{C} 22$ & 0 & 0 & 1 & 0 & 1 & 0 & 1 & 1 & 1 & 0 & 0 & 0 & 0 & 1 & 0 & 1 & 1 & 1 & 1 & 0 & 1 & 1 & 1 & 1 & 0 & 0 & 1 & 1 & 16 & 6 \\
\hline $\mathrm{C} 23$ & 0 & 0 & 1 & 0 & 1 & 0 & 1 & 1 & 1 & 0 & 0 & 0 & 0 & 1 & 0 & 1 & 1 & 1 & 1 & 0 & 1 & 1 & 1 & 1 & 0 & 0 & 1 & 1 & 16 & 6 \\
\hline C24 & 0 & 0 & 1 & 0 & 1 & 0 & 1 & 1 & 1 & 0 & 0 & 0 & 0 & 1 & 0 & 1 & 1 & 1 & 1 & 0 & 1 & 1 & 1 & 1 & 0 & 0 & 1 & 1 & 16 & 6 \\
\hline C25 & 0 & 0 & 1 & 0 & 1 & 0 & 1 & 1 & 1 & 0 & 0 & 0 & 0 & 1 & 0 & 1 & 1 & 1 & 1 & 0 & 1 & 1 & 1 & 1 & 0 & 0 & 1 & 1 & 16 & 6 \\
\hline C26 & 0 & 0 & 1 & 0 & 1 & 0 & 1 & 1 & 1 & 0 & 0 & 0 & 0 & 1 & 0 & 1 & 1 & 1 & 1 & 0 & 1 & 1 & 1 & 1 & 0 & 0 & 1 & 1 & 16 & 6 \\
\hline C27 & 0 & 0 & 1 & 1 & 1 & 0 & 1 & 1 & 1 & 0 & 0 & 0 & 0 & 1 & 0 & 1 & 1 & 1 & 1 & 0 & 1 & 1 & 1 & 1 & 0 & 0 & 0 & 1 & 16 & 6 \\
\hline $\mathrm{C} 28$ & 0 & 0 & 1 & 0 & 1 & 0 & 1 & 1 & 1 & 0 & 0 & 0 & 0 & 1 & 0 & 1 & 1 & 1 & 1 & 0 & 1 & 1 & 1 & 1 & 0 & 0 & 1 & 1 & 16 & 6 \\
\hline
\end{tabular}




\begin{tabular}{|c|c|c|c|c|c|}
\hline Levels & Crite & & $\begin{array}{l}\text { Weight and } \\
\text { Ranking }\end{array}$ & & $\begin{array}{l}\text { Consistency } \\
\left(\varepsilon^{L *}\right)\end{array}$ \\
\hline \multirow[t]{2}{*}{ Level 6} & $\mathrm{C} 22$ & $\begin{array}{l}\text { Landfill spaces saving } \\
\text { measures }\end{array}$ & 0.266 & 1 & 0.040 \\
\hline & $\mathrm{C} 27$ & BIM- based phase planning & 0.238 & 2 & \\
\hline \multirow{6}{*}{$\begin{array}{l}\text { Waste management } \\
\text { operations strategy }\end{array}$} & $\mathrm{C} 25$ & Noise pollution control plans & 0.153 & 3 & \\
\hline & $\mathrm{C} 24$ & Occupational safety measures & 0.102 & 4 & \\
\hline & $\mathrm{C} 23$ & Air pollution control plans & 0.102 & 4 & \\
\hline & $\mathrm{C} 28$ & Public health safety measures & 0.061 & 5 & \\
\hline & $\mathrm{C} 26$ & $\begin{array}{l}\text { Subcontractor green rating } \\
\text { systems }\end{array}$ & 0.051 & 6 & \\
\hline & $\mathrm{C} 21$ & $\begin{array}{l}\text { Operational and overhead } \\
\text { costs mitigation plans }\end{array}$ & 0.028 & 7 & \\
\hline \multirow[t]{2}{*}{ Level 5} & C14 & $\begin{array}{l}\text { Site waste management } \\
\text { effectiveness }\end{array}$ & 0.249 & 1 & 0.042 \\
\hline & C16 & Waste reduction rate & 0.249 & 1 & \\
\hline \multirow{7}{*}{$\begin{array}{c}\text { Site waste management } \\
\text { performance }\end{array}$} & $\mathrm{C9}$ & Waste recycling rate & 0.146 & 2 & \\
\hline & C11 & $\begin{array}{l}\text { Laborer's waste management } \\
\text { knowledge }\end{array}$ & 0.097 & 3 & \\
\hline & $\mathrm{C} 13$ & Waste reusing rate & 0.073 & 4 & \\
\hline & $\mathrm{C} 12$ & Water and land usage & 0.073 & 4 & \\
\hline & $\mathrm{C} 10$ & $\begin{array}{l}\text { Adaptation of modern } \\
\text { construction }\end{array}$ & 0.049 & 5 & \\
\hline & C15 & Eco-designing & 0.042 & 6 & \\
\hline & $\mathrm{C} 17$ & Social image & 0.023 & 7 & \\
\hline Level 4 & C19 & Mutual coordination & 1 & & \\
\hline \multicolumn{6}{|l|}{ Mutual coordination level } \\
\hline Level 3 & C18 & Waste treatment facilities & 1 & & \\
\hline Facility availability & & availability & & & \\
\hline Level 2 & $\mathrm{C} 20$ & Recycled market maturity & 1 & & \\
\hline \multicolumn{6}{|l|}{ Market performance } \\
\hline \multirow[t]{2}{*}{ Level 1} & $\mathrm{C} 1$ & Relevant laws & 0.281 & 1 & 0.030 \\
\hline & $\mathrm{C} 6$ & Social acceptance & 0.281 & 1 & \\
\hline \multirow{6}{*}{$\begin{array}{c}\text { Policy and regulatory } \\
\text { performance }\end{array}$} & $\mathrm{C} 2$ & Level of compliance & 0.155 & 2 & \\
\hline & $\mathrm{C} 3$ & Public awareness & 0.078 & 3 & \\
\hline & $\mathrm{C} 5$ & Taxes and fines & 0.062 & 4 & \\
\hline & $\mathrm{C} 4$ & Incentives & 0.062 & 4 & \\
\hline & $\mathrm{C7}$ & National plans & 0.036 & 5 & \\
\hline & $\mathrm{C} 8$ & Virtual mockup process & 0.044 & 6 & \\
\hline
\end{tabular}

Figure 3. The SWM strategic effectiveness hierarchical framework

\section{Implications}

This section provides theoretical and managerial implications to enhance understanding the strategic effectiveness and performance evaluation of SWM in construction. 


\subsection{Theoretical implications}

This study contributes to the literature by providing a hierarchical framework of SWM strategic effectiveness attributes to compare existing strategies and create integrated waste management measurements to evaluate their performance. The 28 criteria are arranged into six levels and grouped into six aspects that represent attributes for assessing the strategic effectiveness of SWM. These aspects include waste management operations strategy (A1), site waste management performance (A2), mutual coordination level (A3), facility availability (A4), market performance (A5) and policy and regulatory performance (A6). This study suggests that $A 1, A 2$, and $A 3$ are the top level in a structured multilevel model to assess the strategic effectiveness of SWM. Therefore, these three attributes should be the leading indicators for evaluating the effectiveness of the proposed strategies or the performance and progress of the implemented strategy.

The findings show that the highest level is waste management operations strategy (A1). Operational strategy refers to assessing how firms manage their operations in a way that enables them to harness financial benefits while protecting public health and environmental wellbeing (Aslam et al., 2020; Perteghella et al., 2020). The improvement in the firm operational strategy needs to assess the existing management system, such as waste prevention, minimization, recycling, reusing measures. This aspect embodies the extent to which initial decisions and environmental plans intend to use landfills and the accepted levels of pollution involved. Effective strategies need to have higher targets of waste diversion from landfills and restrictions on higher levels of noise and air pollution, which can be achieved by formulating guidelines, providing instructions and employing constant supervision to check the progress of firm sustainability (Chen et al., 2019). Further, providing guidelines for safety, adopting technologies, and setting out a budget for sustainability activities enhances reuse and recycling objectives. Ensuring the greening of firm operations during design phases is the foundation for preventing waste generation from the source, which enhances the surrounding environment and social safety. This aspect also encompasses assessing how the strategy can improve long-term health benefits and reduce expected health problems.

Site waste management performance (A2) was found to be an important attribute in providing insights for decision-makers for the evaluation and ranking of strategic effectiveness. This aspect combines employee sustainability attitudes, knowledge and awareness with the sustainability outcomes of construction activities, such as preserving natural materials, reducing pollution, and improving modern production methods (Kabirifar et al., 2020; Wu et al., 2019). This aspect is also significant in dealing with employee commitment and participation in sustainability for the implementation of construction activities to minimize waste generation and increase waste diversion toward recycling methods. Successful sustainability implementation is engrained in employees' attitudes, experience and knowledge. Employee motivations include providing suggestions about improving production methods, commitment to following SWM plans, and acquiring knowledge to adopt the latest processes. Employee commitment results in waste and pollution generation reduction and increases recycling rates, which are significant indicators for evaluating the strategic effectiveness of SWM. Hence, internal firm assessment to evaluate employee sustainability awareness and knowledge is necessary to assess the effectiveness and monitor the outcomes of firm activities, mainly the amount of waste and pollution levels, which is essential.

Another driving aspect is mutual coordination (A3); this study confirmed that the mutual coordination level (A3) plays a significant role in assessing the strategic effectiveness and performance of SWM. Different construction stakeholders' diverse interests, plans, and 
attitudes make it challenging to implement strategies effectively; hence, developing coordination among them is necessary. This aspect refers to the existence of policies and procedures intended to facilitate cooperation among stakeholders and balance their diverse interests. It assists by providing a thoughtful arrangement of stakeholder-related attributes to attain the strategic effectiveness of SWM, which can be achieved by efficient communication and transparent information sharing (Jin et al., 2019; Li et al., 2020). Forming a coordination team that ensures the understanding, engagement, and participation of all stakeholders in implementing coordinated strategies is also essential for achieving higher levels of coordination (Won \& Cheng, 2017). Proposing indicators for evaluating the mutual coordination level and plans for integrating stakeholders' efforts into existing strategies is a prerequisite for assessing the strategic effectiveness of SWM. Due to the nature of construction activities as collaborative work, incorporating policies that drive stakeholder understanding and collaboration in any waste management strategy is necessary.

\subsection{Managerial implications}

This study finds that the waste reduction rate (C16), waste recycling rate (C9), reuse rate (C13), noise pollution (C25), and air pollution (C23) have high dependence and driving power and profoundly influence the other criteria. Thus, these criteria are critical measures that assist decision-makers in forming an effective SWM strategy and improving overall performance by addressing these issues.

Reducing waste (C16) is essential for assessing sustainability performance and progress toward waste minimization and natural resource preservation. This criterion is also found to be a significant attribute that can indicate the strategic effectiveness of SWM by targeting lower waste production by avoiding materials and practices with higher potential for waste generation. Waste generation can be reduced by integrating waste minimization techniques in the early phases of construction activity, such as design, using green materials, avoiding material estimation errors, and hiring sustainability-conscious labor. The SWM strategy must contain specific, measurable, achievable, realistic, time-oriented targets for waste reduction and increase the concepts of recycling and reuse for the progress of sustainability in waste management.

The recycling rate (C9) involves the amount of waste recycled or recovered from the total waste generated. Higher targets of recycled waste proportions denote greater strategic effectiveness, which brings about greater benefits such as protecting raw materials, saving energy for new material production, creating value from waste, and saving landfill space. In contrast, there are difficulties involved in recycling activities, such as higher initial costs for facilities, technology and collection, energy consumption, pollution from the recycling process and lower quality of recycled products. Because of this, it is necessary to corroborate to enhance recycling efficiency, which can be achieved by involving the critical success factors leading to the smooth implementation of the recycling process. Efficient recycling involves using recyclable materials, high collection rate targets, site-based segregation of materials, and economic feasibility studies on return policies, which motivate and assist practitioners in understanding and applying the recycling process. This study finds that the strategic effectiveness of SWM requires realistic recycling rate targets that guide decision-makers and balance the financial gains of firms with sustainability goals.

The amount of waste reused (C13) is found to be beneficial when comparing the existing strategic effectiveness of SWM, tracking the progress of sustainability, and measuring performance. Although reuse is a form of recycling, the amount of energy needed and the cost 
to reuse materials are much less than the energy consumption and expenses involved in recycling. Furthermore, construction materials, such as bricks, tiles, blocks, steel, and plywood, are reusable, and waste materials from one site can be shared with another site that needs them, making reuse preferable over recycling activities. Waste management strategies must incorporate strategies to preserve and prolong material usage for the longest possible time to achieve a higher effectiveness level. Effective SWM targets a higher reuse ratio by obtaining reliable and accurate information about input material quality and characteristics during the construction design and material estimation phases, particularly the durability and repurposing potential. Additionally, by providing guidelines for design and disassembly and employing reverse logistics approaches, this study asserts that the target of reusing the SWM strategy is related to the expected effectiveness; a higher targeted ratio is linked with higher performance and effectiveness. Hence, decision-makers choosing between the existing SWM strategies can prioritize and select a strategy to adopt by assessing the expected amount of reuse of materials.

Noise pollution (C25) levels coming from construction sites, such as that generated by machinery, heavy equipment and vehicles, have social and environmental impacts on the surroundings, especially near sensitive areas such as hospitals, schools, and residential areas. SWM strategies must include measures to reduce this noise, as it is related to diseases such as nervous and vascular diseases, sleep disorders, and headaches. Construction management decision-makers believe that a high level of noise is inevitable in construction sites. However, adopting noise pollution controls during the planning stage by predicting the sound frequency, duration and activities producing sound can assist in preventing high levels of noise. Having information about the noise source enables practitioners to schedule noisy activities for a suitable time, prepare proper technology such as sound-absorbing devices, use less noisy practices and equipment and provide appropriate personal protective equipment for site workers. This study asserts that the strategic effectiveness of SWM highly depends on the amount of noise pollution related to it; the lower the acceptable noise pollution level is, the more effective the strategy. Hence, decision-makers must look at noise pollution policies attentively when comparing and choosing an effective SWM strategy.

Evaluating air pollution (C23) levels of construction is a significant criterion that involves assessing the amount of air pollution resulting from clearing land, engine diesel combustion, demolition, and other toxic materials in construction. Resolving dust pollution issues is a key step in attaining sustainable construction, and dust and emissions from construction are related to health problems, mainly lung and respiratory system problems. Booming construction and demolition work have led to higher levels of construction dust pollution. Hence, waste management needs to incorporate preventive measures to mitigate air pollution from construction activities, which can be achieved by providing detailed information about construction dust sources. Poor air quality is the most direct pollution effect from a construction site due to its proximity to residential areas and materials used. Airborne contaminants, such as volatile compounds and contaminated particulate matter, are blown around by the wind and can travel long distances in a short amount of time. The direction of the wind impacts the area most affected by air pollution around a construction site. Enclosing the construction site to prevent dust from spreading, watering excavated soils, demolishing debris, and covering transported soil can prevent the pollution effect from a construction site.

\section{Conclusions}


The waste generated from construction activities has become the focal point of SWM strategies. Diverse strategic frameworks of waste management have emerged; however, prior studies have neglected to develop attributes for assessing the strategic effectiveness and performance of SWM. This study performed a content analysis on SWM strategic effectiveness attributes to propose 75 criteria. The FDM was employed to arrive at valid SWM strategic effectiveness measures; after two rounds of Delphi assessment, 28 criteria were validated. The FISM method was then applied to arrange the validated criteria into an integrated hierarchical framework. The result divides the attributes into six aspects and constructs a multilevel model that depicts the interrelationships. The BWM is applied to determine the weight of the criteria in the SWM strategic effectiveness hierarchical framework. These methods are used to address expert linguistic preference uncertainty by transforming the fuzzy linguistic responses of experts into crisp values and enabling qualitative information to be assessed. The proposed hierarchical framework integrating the SWM strategic effectiveness attributes represents the contributions of this study to theory.

In this study, a hierarchical assessment framework for the strategic effectiveness of SWM composed of 6 aspects and 28 criteria is developed. The aspects include waste management operations strategy, site waste management performance, mutual coordination level, facility availability, market performance and policy and regulatory performance. The three aspects with the highest importance in the hierarchical framework are waste management operational strategy, site waste management performance, and mutual coordination. The results showed that nine criteria have significant dependent and driving powers and are critical measures that assist decision-makers in forming an effective SWM strategy and improving overall performance. The linkage criteria include waste reduction rate, waste recycling rate, reuse rate, noise pollution, and air pollution, water and land usage, impacts on long-term health, amount of landfill space saved, eco-design adaptation, and the existence of site waste management plans. These criteria can provide decision-makers with insightful measures to compare SWM strategies and choose the most effective strategy to achieve higher sustainability performance.

Hence, this study provides theoretical and managerial contributions for SWM in construction and contributes to the literature by providing a hierarchical framework of SWM strategic effectiveness attributes to assess the existing strategies and create integrated waste management measurements. The theoretical and managerial implications and suggestions were provided based on the findings' top influential and decisive aspects and criteria. This study asserts that waste management operations strategy, site waste management performance, mutual coordination level are the decisive aspects of the strategic effectiveness of SWM, which can be used for monitoring and assessing. The study also provides practitioners with detailed guidelines related to the top linkage criteria for selecting an effective waste management strategy, evaluating its progress, and finally, re-evaluating its final performance.

Nevertheless, this study has limitations. First, the proposed attributes were gathered from the literature, which might limit the completeness of the proposed framework. Hence, future studies should integrate more attributes into the framework to deepen the findings of this study. Second, the study used responses from 18 experts; this limited number of responses might cause biased results, and thus, increasing the number of experts is suggested to obtain a more comprehensive discussion. Future studies might use this hierarchical framework to demonstrate the strategic effectiveness and performance of SWM in other industries.

\section{Data Availability Statement}


Some or all data that support the findings of this study are available from the corresponding author upon reasonable request.

\section{Author Contributions}

Yeneneh Tamirat Negash- Conceptualize, original version and finalized the final version; Abdiqani Muse Hassan- Conceptualize, original version and finalized the final version;MingLang Tseng- Conceptualize, original version and finalized the final version;Mohd Helmi AliOriginal version and finalized the final version; and Ming K. Lim- Original version and finalized the final version;

\section{Availability of data and materials}

No authorized

\section{Consent to Participate}

783

784

\section{Consent to Publish}

Not applicable

\section{Competing Interests}

Not applicable

\section{Ethical Approval}

Not applicable

\section{Funding Declaration}

This study is partially supported from MOST 110-2221-E-468 -010 -, Ministry of Science and Technology, Taiwan

\section{References}

Abarca-Guerrero, L., Maas, G., \& Van Twillert, H. (2017). Barriers and motivations for construction waste reduction practices in Costa Rica. Resources, 6(4), 69.

Ajayi, S. O., Oyedele, L. O., Bilal, M., Akinade, O. O., Alaka, H. A., Owolabi, H. A., \& Kadiri, K. O. (2015). Waste effectiveness of the construction industry: Understanding the impediments and requisites for improvements. Resources, Conservation and Recycling, 102, 101-112.

Ajayi, S. O., Oyedele, L. O., Bilal, M., Akinade, O. O., Alaka, H. A., \& Owolabi, H. A. (2017). Critical management practices influencing on-site waste minimization in construction projects. Waste Management, 59, 330-339.

Ajayi, S. O., Oyedele, L. O., Akinade, O. O., Bilal, M., Alaka, H. A., \& Owolabi, H. A. (2017). Optimising material procurement for construction waste minimization: An exploration of success factors. Sustainable Materials and Technologies, 11, 38-46.

Ahangar, S.S., Sadati, A., \& Rabbani, M. (2021) Sustainable design of a municipal solid waste management system in an integrated closed-loop supply chain network using a fuzzy approach: a case study. Journal of Industrial and Production Engineering, 38(5), 323-340

Alnajem, M., Mostafa, M.M. \& ElMelegy, A.R. (2021), Mapping the first decade of circular economy research: a bibliometric network analysis, Journal of Industrial and Production Engineering, 38(1), 29-50 
Aslam, M. S., Huang, B., \& Cui, L. (2020). Review of construction and demolition waste management in China and USA. Journal of Environmental Management, 264, 110445.

Bao, Z., \& Lu, W. (2020). Developing efficient circularity for construction and demolition waste management in fast emerging economies: Lessons learned from Shenzhen, China. Science of The Total Environment, 742, 138264.

Blaisi, N. I. (2019). Construction and demolition waste management in Saudi Arabia: current practice and roadmap for sustainable management. Journal of Cleaner Production, 221, 167-175.

Borghi, G., Pantini, S., \& Rigamonti, L. (2018). Life cycle assessment of non-hazardous Construction and Demolition Waste (CDW) management in Lombardy Region (Italy). Journal of Cleaner Production, 184, 815-825.

Bui, T. D., Tsai, F. M., Tseng, M. L., Wu, K. J., \& Chiu, A. S. (2020). Effective municipal solid waste management capability under uncertainties in Vietnam: utilizing economic efficiency and technology to foster social mobilization and environmental integrity. Journal of Cleaner Production, 259, 120981.

Bui, TD., \& Tseng, ML (2021). Understanding the barriers to sustainable solid waste management in society 5.0 under uncertainties: A novelty of socials and technical perspectives on performance driving. Environmental Science and Pollution Research (Article in Press)

Chen, J., Hua, C., \& Liu, C. (2019). Considerations for better construction and demolition waste management: Identifying the decision behaviors of contractors and government departments through a game theory decision-making model. Journal of Cleaner Production, 212, 190-199.

Di Bella, V., \& Vaccari, M. (2014). Constraints for solid waste management in Somaliland. Proceedings of the Institution of Civil Engineers-Waste and Resource Management. 167(2). 62-71.

Ding, Z., Zhu, M., Tam, V. W., Yi, G., \& Tran, C. N. (2018). A system dynamics-based environmental benefit assessment model of construction waste reduction management at the design and construction stages. Journal of Cleaner Production, 176, 676-692.

Du, L., Feng, Y., Lu, W., Kong, L., \& Yang, Z. (2020). Evolutionary game analysis of stakeholders' decision-making behaviors in construction and demolition waste management. Environmental Impact Assessment Review, 84, 106408.

Esa, M. R., Halog, A., \& Rigamonti, L. (2017). Strategies for minimizing construction and demolition wastes in Malaysia. Resources, Conservation and Recycling, 120, 219-229.

Rezaei, J. (2016). Best-worst multi-criteria decision-making method: Some properties and a linear model. Omega, 64, 126-130.

Rezaei, J. (2015). Best-worst multi-criteria decision-making method. Omega, 53, 49-57.

Ghaffar, S. H., Burman, M., \& Braimah, N. (2020). Pathways to circular construction: An integrated management of construction and demolition waste for resource recovery. Journal of Cleaner Production, 244, 118710.

Goh, C. S., Chong, H. Y., Jack, L., \& Faris, A. F. M. (2020). Revisiting triple bottom line within the context of sustainable construction: A systematic review. Journal of Cleaner Production, 252, 119884.

Govindan, K., Palaniappan, M., Zhu, Q., \& Kannan, D. (2012). Analysis of third-party reverse logistics provider using interpretive structural modeling. International Journal of Production Economics, 140(1), 204-211. 
Hao, J., Yuan, H., Liu, J., Chin, C. S., \& Lu, W. (2019). A model for assessing the economic performance of construction waste reduction. Journal of Cleaner Production, 232, 427440.

He, L., \& Yuan, H. (2020). Investigation of construction waste recycling decisions by considering consumers' quality perceptions. Journal of Cleaner Production, 120928.

Huang, B., Wang, X., Kua, H., Geng, Y., Bleischwitz, R., \& Ren, J. (2018). Construction and demolition waste management in China through the 3Rs principle. Resources, Conservation and Recycling, 129, 36-44.

Illankoon, I. C. S., \& Lu, W. (2020). Cost implications of obtaining construction waste management-related credits in green building. Waste Management, 102, 722-731.

lacovidou, E., Busch, J., Hahladakis, J. N., Baxter, H., Ng, K. S., \& Herbert, B. M. (2017). A parameter selection framework for sustainability assessment. Sustainability, 9(9), 1497.

Jin, R., Li, B., Zhou, T., Wanatowski, D., \& Piroozfar, P. (2017). An empirical study of perceptions towards construction and demolition waste recycling and reuse in China. Resources, Conservation and Recycling, 126, 86-98.

Jin, R., Yuan, H., \& Chen, Q. (2019). Science mapping approach to assisting the review of construction and demolition waste management research published between 2009 and 2018. Resources, Conservation and Recycling, 140, 175-188.

Kabirifar, K., Mojtahedi, M., Wang, C., \& Tam, V. W. (2020). Construction and demolition waste management contributing factors coupled with reduce, reuse, and recycle strategies for effective waste management: A review. Journal of Cleaner Production, 121265.

Khan, A. H., López-Maldonado, E. A., Khan, N. A., Villarreal-Gómez, L. J., Munshi, F. M., Alsabhan, A. H., \& Perveen, K. (2021). Current solid waste management strategies and energy recovery in developing countries-State of art review. Chemosphere, 133088.

Lavigne, C., De Jaeger, S., \& Rogge, N. (2019). Identifying the most relevant peers for benchmarking waste management performance: a conditional directional distance Benefit-of-the-Doubt approach. Waste Management, 89, 418-429.

Li, C. Z., Zhao, Y., Xiao, B., Yu, B., Tam, V. W., Chen, Z., \& Ya, Y. (2020). Research trend of the application of information technologies in construction and demolition waste management. Journal of Cleaner Production, 121458.

Lu, W., Chi, B., Bao, Z., \& Zetkulic, A. (2019). Evaluating the effects of green building on construction waste management: A comparative study of three green building rating systems. Building and Environment, 155, 247-256.

Mahpour, A., \& Mortaheb, M. M. (2018). Financial-based incentive plan to reduce construction waste. Journal of Construction Engineering and Management, 144(5), 04018029.

Marrero, M., Puerto, M., Rivero-Camacho, C., Freire-Guerrero, A., \& Solís-Guzmán, J. (2017). Assessing the economic impact and ecological footprint of construction and demolition waste during the urbanization of rural land. Resources, Conservation and Recycling, 117, 160-174.

Negash, Y. T., \& Hassan, A. M. (2020). Construction Project Success under Uncertainty: Interrelations among the External Environment, Intellectual Capital, and Project Attributes. Journal of Construction Engineering and Management, 146(10), 05020012.

Negash, Y. T., Sarmiento, L. S. C., Tseng, M. L., Jantarakolica, K., \& Tan, K. (2021). Sustainable product-service system hierarchical framework under uncertainties: The pharmaceutical industry in Ecuador. Journal of Cleaner Production, 294, 126188.

Omar, A.M., Fashina, A.A., \& Fakunle, F.F. (2020). The status quo of Somaliland construction industry: A development trend. PM World Journal, 11(5). 
Perteghella, A., Gilioli, G., Tudor, T., \& Vaccari, M. (2020). Utilizing an integrated assessment scheme for sustainable waste management in low and middle-income countries: Case studies from Bosnia-Herzegovina and Mozambique. Waste Management, 113, 176-185.

Ruiz, L. A. L., Ramón, X. R., \& Domingo, S. G. (2020). The circular economy in the construction and demolition waste sector-a review and an integrative model approach. Journal of Cleaner Production, 248, 119238.

Sadeghi Ahangar, S., Sadati, A., \& Rabbani, M. (2021). Sustainable design of a municipal solid waste management system in an integrated closed-loop supply chain network using a fuzzy approach: A case study. Journal of Industrial and Production Engineering, 1-18.

Tseng, M. L., Tran, T. P. T., Ha, H. M., Bui, T. D., \& Lim, M. K. (2021). Sustainable industrial and operation engineering trends and challenges Toward Industry 4.0: A data driven analysis. Journal of Industrial and Production Engineering, 38(8), 581-598.

Tseng, M. L., Wu, K. J., Chiu, A. S., Lim, M. K., \& Tan, K. (2019). Reprint of: Service innovation in sustainable product service systems: Improving performance under linguistic preferences. International Journal of Production Economics, 217, 159-170.

Tsai, F. M., Bui, T. D., Tseng, M. L., Wu, K. J., \& Chiu, A. S. (2020). A performance assessment approach for integrated solid waste management using a sustainable balanced scorecard approach. Journal of Cleaner Production, 251, 119740.

Um, N., Kang, Y. Y., Kim, K. H., Shin, S. K., \& Lee, Y. (2018). Strategic environmental assessment for effective waste management in Korea: A review of the new policy framework. Waste Management, 82, 129-138.

Won, J., \& Cheng, J. C. (2017). Identifying potential opportunities of building information modeling for construction and demolition waste management and minimization. Automation in Construction, 79, 3-18.

Wu, H., Zuo, J., Yuan, H., Zillante, G., \& Wang, J. (2019). A review of performance assessment methods for construction and demolition waste management. Resources, Conservation and Recycling, 150, 104407.

Xu, J., Shi, Y., \& Zhao, S. (2019). Reverse logistics network-based multiperiod optimization for construction and demolition waste disposal. Journal of Construction Engineering and Management, 145(2), 04018124.

Yuan, H., Chini, A. R., Lu, Y., \& Shen, L. (2012). A dynamic model for assessing the effects of management strategies on the reduction of construction and demolition waste. Waste Management, 32(3), 521-531.

Yuan, H. (2017). Barriers and countermeasures for managing construction and demolition waste: A case of Shenzhen in China. Journal of Cleaner Production, 157, 84-93.

Yuan, H. (2013). Key indicators for assessing the effectiveness of waste management in construction projects. Ecological Indicators, 24, 476-484.

Zhang, H., Yin, C., Qi, X., Zhang, R., \& Kang, X. (2017). Cognitive best worst method for multiattribute decision-making. Mathematical Problems in Engineering, 2017, Article ID 1092925. 
980 Appendix A. List of proposed criteria

\begin{tabular}{|c|c|c|}
\hline \multicolumn{2}{|c|}{ Initial Criteria } & \multirow{2}{*}{$\begin{array}{l}\text { References } \\
\text { Esa et al. 2017; Li et al., } 2018\end{array}$} \\
\hline IC1 & Mutual coordination & \\
\hline IC2 & Collaboration & Abarca-Guerrero et al., 2017; Esa et al. 2017 \\
\hline IC3 & Top management attitude & Aslam et al., 2020 \\
\hline IC4 & Communication easiness & Kabirifar et al., 2020 \\
\hline IC5 & Laborer's Attitudes & Esa et al. 2017; Li et al., 2018; Kabirifar et al., 2020 \\
\hline IC6 & Public awareness & Esa et al. 2017; Chen et al., 2019; Aslam et al., 2020 \\
\hline IC7 & Education and training platforms & $\begin{array}{l}\text { Abarca-Guerrero et al., 2017; Esa et al. 2017; Ghaffar et } \\
\text { al., } 2020\end{array}$ \\
\hline IC8 & Green sub-contractor preference & Kabirifar et al., 2020 \\
\hline IC9 & Provision of job opportunities & Li et al., 2018; Ghaffar et al., 2020 \\
\hline IC10 & Physical working condition & Esa et al. 2017; Ghaffar et al., 2020 \\
\hline IC11 & Social image & Kabirifar et al., 2020 \\
\hline IC12 & Public appeals & Esa et al. 2017; Aslam et al., 2020 \\
\hline IC13 & Safe practices & Ghaffar et al., 2020 \\
\hline IC14 & Social acceptance & Ghaffar et al., 2020 \\
\hline IC15 & Recycling practices & Ajayi et al., 2017; Li et al., 2020; Ruiz et al., 2020 \\
\hline IC16 & Eco-designing & Ruiz et al., 2020 \\
\hline IC17 & Modular designing & Won and Cheng, 2017; Esa et al. 2017 \\
\hline IC18 & Design changes & Jin et al., 2019; Li et al., 2020 \\
\hline IC19 & Design document compliance & Esa et al. 2017; Ajayi et al., 2017 \\
\hline IC20 & Site waste management plans & Ruiz et al., 2020 \\
\hline
\end{tabular}




\begin{tabular}{|c|c|c|}
\hline IC21 & Adaptation of modern construction & Li et al., 2020 \\
\hline IC22 & Technology application level & Won and Cheng, 2017; Chen et al., 2019 \\
\hline IC23 & Waste sorting level & Jin et al., 2019; Ruiz et al., 2020 \\
\hline IC24 & Selective deconstruction & Jin et al., 2019; Ruiz et al., 2020 \\
\hline IC25 & Waste quantity prediction & Esa et al. 2017; Li et al., 2020 \\
\hline IC26 & Accuracy of material estimation & Jin et al., 2019 \\
\hline IC27 & Green material selection & Ajayi et al., 2017; Ruiz et al., 2020 \\
\hline IC28 & Material safe handling & Ajayi et al., 2017; Ruiz et al., 2020 \\
\hline IC29 & $\begin{array}{l}\text { Building information modeling -based } \\
\text { phase planning }\end{array}$ & Chen et al., 2019 \\
\hline IC30 & Quantity take-off & Chen et al., 2019 \\
\hline IC31 & A design review & Chen et al., 2019 \\
\hline IC32 & Clash detection & Chen et al., 2019 \\
\hline IC33 & Site utilization planning & Chen et al., 2019 \\
\hline IC34 & A 3D control and planning & Chen et al., 2019 \\
\hline IC35 & Digital fabrication & Ajayi et al., 2017; Ruiz et al., 2020 \\
\hline IC36 & Virtual mockup process & Ajayi et al., 2017; Ruiz et al., 2020 \\
\hline IC37 & Operational costs & Kabirifar et al., 2020 \\
\hline IC38 & Incentives & He and Yuan, 2020 \\
\hline IC39 & Economic feasibility studies & He and Yuan, 2020 \\
\hline IC40 & Research investments & Yusof et al., 2017 \\
\hline IC41 & Waste management budget & Hao et al., 2019; \\
\hline IC42 & Disposal/treatment costs & Galves Martoz et al., 2018 \\
\hline IC43 & Recycling charge & Galves Martoz et al., 2018 \\
\hline IC44 & Landfill charge & Galves Martoz et al., 2018 \\
\hline IC45 & Cost for equipment & He and Yuan, 2020 \\
\hline IC46 & Recycled market maturity & He and Yuan, 2020 \\
\hline IC47 & Impacts on long-term health & Ajayi et al., 2017; Borghi et al. 2018 \\
\hline IC48 & Generated waste & Yuan, 2013; Ding et al. 2017 \\
\hline IC49 & Reduced waste & Hao et al., 2019; Ruiz et al., 2020 \\
\hline IC50 & Recycled waste & Hao et al., 2019; Ruiz et al., 2020 \\
\hline IC51 & Reused waste & Hao et al., 2019; Ruiz et al., 2020 \\
\hline IC52 & Site bins availability & Ding et al. 2017; Ajayi et al., 2017 \\
\hline IC53 & Treatment facilities & Ding et al. 2017; Ajayi et al., 2017 \\
\hline IC54 & Waste generation & Hao et al., 2019; Ruiz et al., 2020 \\
\hline IC55 & Prioritization of materials recycling & Ajayi et al., 2017 \\
\hline IC56 & Prioritization of policy and technology & Ajayi et al., 2017 \\
\hline IC57 & Site supervision & Ding et al. 2017; Ruiz et al., 2020 \\
\hline IC58 & Arbitrary performance outcomes & Ding et al. 2017; Ajayi et al., 2017 \\
\hline IC59 & Technical performance outcomes & Ding et al. 2017; Ajayi et al., 2017 \\
\hline IC60 & Landfill rate & Ding et al. 2017; Ajayi et al., 2017 \\
\hline IC61 & Landfill spaces & Ding et al. 2017; Ajayi et al., 2017 \\
\hline IC62 & Noise pollution & Ruiz et al., 2020 \\
\hline IC63 & Air pollution & Ruiz et al., 2020 \\
\hline IC64 & Water and land pollution & Ruiz et al., 2020 \\
\hline IC65 & Public environment condition & Ajayi et al., 2017; Hao et al., 2019 \\
\hline IC66 & Environmental management & Ajayi et al., 2017; Hao et al., 2019 \\
\hline IC67 & Taxes and fines & Jin et al., 2017; Li et al., 2020 \\
\hline IC68 & Government recycling targets & Esa et al., 2017; Jin et al., 2019 \\
\hline IC69 & National plans & Jin et al., 2017; Li et al., 2020 \\
\hline
\end{tabular}




\begin{tabular}{lll}
\hline IC70 & Relevant laws & Yusof et al., 2017; Abarca-Guerrero et al., 2017 \\
IC71 & Level of compliance & Yusof et al., 2017; Abarca-Guerrero et al., 2017 \\
IC72 & Licensed waste disposal & Yusof et al., 2017; Abarca-Guerrero et al., 2017 \\
IC73 & Plan adherence contract & Abarca-Guerrero et al., 2017; Jin et al., 2019 \\
IC74 & Mandatory reporting & Abarca-Guerrero et al., 2017; Jin et al., 2019 \\
IC75 & Audit and inspection setup & Abarca-Guerrero et al., 2017; Jin et al., 2019 \\
\hline
\end{tabular}

981

982 
984 Appendix B. FDM round 1 screening out for criteria

\begin{tabular}{|c|c|c|c|}
\hline \multicolumn{2}{|c|}{ Initial Criteria } & \multirow{2}{*}{$\frac{\text { Weight }}{0.644}$} & \multirow{2}{*}{$\frac{\text { Decision }}{\text { Accepted }}$} \\
\hline IC1 & Mutual coordination & & \\
\hline IC2 & Collaboration & 0.621 & Accepted \\
\hline IC3 & Top management attitude & 0.658 & Accepted \\
\hline IC4 & Communication easiness & 0.668 & Accepted \\
\hline IC5 & Laborer's Attitudes & 0.797 & Accepted \\
\hline IC6 & Public awareness & 0.797 & Accepted \\
\hline IC7 & Education and training platforms & 0.333 & Rejected \\
\hline IC8 & Green sub-contractor preference & 0.633 & Accepted \\
\hline IC9 & Provision of job opportunities & 0.333 & Rejected \\
\hline IC10 & Physical working condition & 0.686 & Accepted \\
\hline IC11 & Social image & 0.678 & Accepted \\
\hline IC12 & Public appeals & 0.694 & Accepted \\
\hline IC13 & Safe practices & 0.655 & Accepted \\
\hline IC14 & Social acceptance & 0.815 & Accepted \\
\hline IC15 & Recycling practices & 0.333 & Rejected \\
\hline IC16 & Eco-designing & 0.691 & Accepted \\
\hline IC17 & Modular designing & 0.665 & Accepted \\
\hline IC18 & Design changes & 0.665 & Accepted \\
\hline IC19 & Design document compliance & 0.333 & Rejected \\
\hline IC20 & Site waste management plans & 0.789 & Accepted \\
\hline IC21 & Adaptation of modern construction & 0.680 & Accepted \\
\hline IC22 & Technology application level & 0.648 & Accepted \\
\hline IC23 & Waste sorting level & 0.668 & Accepted \\
\hline IC24 & Selective deconstruction & 0.333 & Rejected \\
\hline IC25 & Waste quantity prediction & 0.683 & Accepted \\
\hline IC26 & Accuracy of material estimation & 0.333 & Rejected \\
\hline IC27 & Green material selection & 0.665 & Accepted \\
\hline IC28 & Material safe handling & 0.333 & Rejected \\
\hline IC29 & Building information modeling based phase planning & 0.806 & Accepted \\
\hline IC30 & Quantity take-off & 0.476 & Rejected \\
\hline IC31 & A design review & 0.333 & Rejected \\
\hline IC32 & Clash detection & 0.333 & Rejected \\
\hline IC33 & Site utilization planning & 0.333 & Rejected \\
\hline IC34 & A 3D control and planning & 0.333 & Rejected \\
\hline IC35 & Digital fabrication & 0.333 & Rejected \\
\hline IC36 & Virtual mockup process & 0.655 & Accepted \\
\hline IC37 & Operational costs & 0.668 & Accepted \\
\hline IC38 & Incentives & 0.658 & Accepted \\
\hline IC39 & Economic feasibility studies & 0.333 & Rejected \\
\hline IC40 & Research investments & 0.702 & Accepted \\
\hline
\end{tabular}




\begin{tabular}{|c|c|c|c|}
\hline IC41 & Waste management budget & 0.680 & Accepted \\
\hline IC42 & Disposal/treatment costs & 0.651 & Accepted \\
\hline IC43 & Recycling charge & 0.668 & Accepted \\
\hline IC44 & Landfill charge & 0.648 & Accepted \\
\hline IC45 & Cost for equipment & 0.333 & Rejected \\
\hline IC46 & Recycled market maturity & 0.639 & Accepted \\
\hline IC47 & Impacts on long-term health & 0.699 & Accepted \\
\hline IC48 & Generated waste & 0.333 & Rejected \\
\hline IC49 & Reduced waste & 0.765 & Accepted \\
\hline IC50 & Recycled waste & 0.797 & Accepted \\
\hline IC51 & Reused waste & 0.773 & Accepted \\
\hline IC52 & Site bins availability & 0.333 & Rejected \\
\hline IC53 & Treatment facilities & 0.633 & Accepted \\
\hline IC54 & Waste generation & 0.333 & Rejected \\
\hline IC55 & Prioritization of materials recycling & 0.333 & Rejected \\
\hline IC56 & Prioritization of policy and technology & 0.333 & Rejected \\
\hline IC57 & Site supervision & 0.333 & Rejected \\
\hline IC58 & Arbitrary performance outcomes & 0.333 & Rejected \\
\hline IC59 & Technical performance outcomes & 0.333 & Rejected \\
\hline IC60 & Landfill rate & 0.780 & Accepted \\
\hline IC61 & Landfill spaces & 0.780 & Accepted \\
\hline IC62 & Noise pollution & 0.789 & Accepted \\
\hline IC63 & Air pollution & 0.797 & Accepted \\
\hline IC64 & Water and land pollution & 0.815 & Accepted \\
\hline IC65 & Public environment condition & 0.672 & Accepted \\
\hline IC66 & Environmental management & 0.333 & Rejected \\
\hline IC67 & Taxes and fines & 0.646 & Accepted \\
\hline IC68 & Government recycling targets & 0.333 & Rejected \\
\hline IC69 & National plans & 0.651 & Accepted \\
\hline IC70 & Relevant laws & 0.806 & Accepted \\
\hline IC71 & Level of compliance & 0.780 & Accepted \\
\hline IC72 & Licensed waste disposal & 0.333 & Rejected \\
\hline IC73 & Plan adherence contract & 0.333 & Rejected \\
\hline IC74 & Mandatory reporting & 0.333 & Rejected \\
\hline IC75 & Audit and inspection setup & 0.333 & Rejected \\
\hline
\end{tabular}

985

986 Appendix C. FDM round 2 screening out for criteria

\begin{tabular}{llll}
\hline Initial Name & Criteria & Weight & Decision \\
\hline IC1 & Mutual coordination & 0.648 & Accepted \\
IC2 & Collaboration & 0.333 & Rejected \\
IC3 & Top management attitude & 0.333 & Rejected \\
IC4 & Communication easiness & 0.333 & Rejected \\
\hline
\end{tabular}




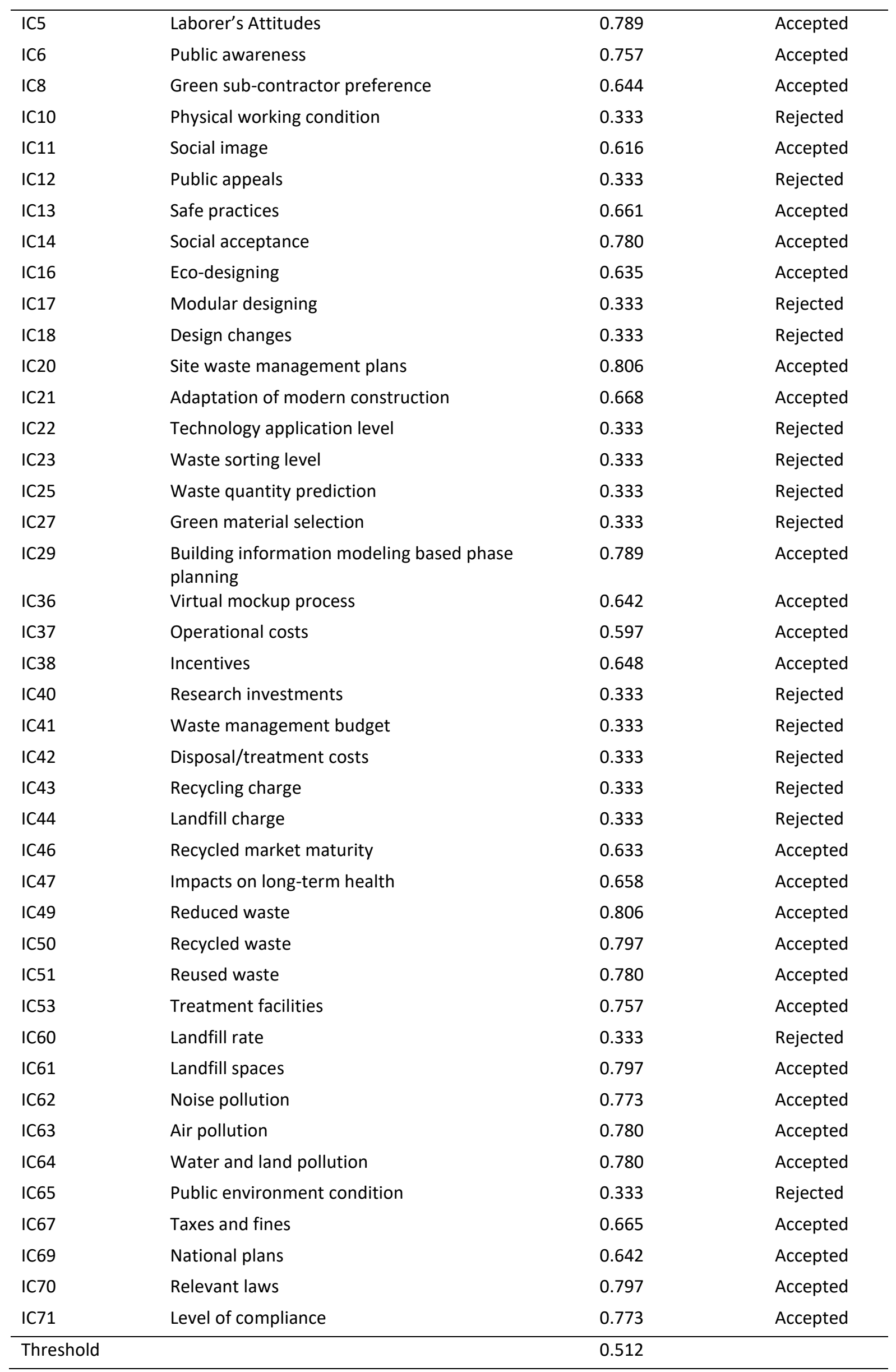



Appendix D. List of FDM final criteria result

\begin{tabular}{|c|c|c|c|c|}
\hline Initial name & Renamed & Criteria & Weight & Decision \\
\hline IC1 & $\mathrm{C} 1$ & Mutual coordination & 0.648 & Accepted \\
\hline IC5 & $\mathrm{C} 2$ & Laborer's Attitudes & 0.789 & Accepted \\
\hline IC6 & $\mathrm{C} 3$ & Public awareness & 0.757 & Accepted \\
\hline IC7 & $\mathrm{C} 4$ & Green sub-contractor preference & 0.644 & Accepted \\
\hline IC9 & $\mathrm{C} 5$ & Social image & 0.616 & Accepted \\
\hline IC11 & C6 & Safe practices & 0.661 & Accepted \\
\hline IC12 & $\mathrm{C7}$ & Social acceptance & 0.780 & Accepted \\
\hline IC13 & $\mathrm{C} 8$ & Eco-designing & 0.635 & Accepted \\
\hline IC16 & C9 & Site waste management plans & 0.806 & Accepted \\
\hline IC17 & C10 & Adaptation of modern construction & 0.668 & Accepted \\
\hline IC22 & C11 & $\begin{array}{l}\text { Building information modeling based phase } \\
\text { planning }\end{array}$ & 0.789 & Accepted \\
\hline IC23 & $\mathrm{C} 12$ & Virtual mockup process & 0.642 & Accepted \\
\hline IC24 & $\mathrm{C} 13$ & Operational costs & 0.597 & Accepted \\
\hline IC25 & C14 & Incentives & 0.648 & Accepted \\
\hline IC31 & C15 & Recycled market maturity & 0.633 & Accepted \\
\hline IC32 & C16 & Impacts on long-term health & 0.658 & Accepted \\
\hline IC33 & $\mathrm{C} 17$ & Reduced waste & 0.806 & Accepted \\
\hline IC34 & C18 & Recycled waste & 0.797 & Accepted \\
\hline IC35 & C19 & Reused waste & 0.780 & Accepted \\
\hline IC36 & $\mathrm{C} 20$ & Treatment facilities & 0.757 & Accepted \\
\hline IC38 & $\mathrm{C} 21$ & Landfill spaces & 0.797 & Accepted \\
\hline IC39 & $\mathrm{C} 22$ & Noise pollution & 0.773 & Accepted \\
\hline IC40 & $\mathrm{C} 23$ & Air pollution & 0.780 & Accepted \\
\hline IC41 & $\mathrm{C} 24$ & Water and land pollution & 0.780 & Accepted \\
\hline IC43 & $\mathrm{C} 25$ & Taxes and fines & 0.665 & Accepted \\
\hline IC44 & $\mathrm{C} 26$ & National plans & 0.642 & Accepted \\
\hline IC45 & $\mathrm{C} 27$ & Relevant laws & 0.797 & Accepted \\
\hline IC46 & $\mathrm{C} 28$ & Level of compliance & 0.773 & Accepted \\
\hline
\end{tabular}




\section{Supplementary Files}

This is a list of supplementary files associated with this preprint. Click to download.

- 202112260903GraphicalAbstract.pdf 